\title{
Acquisition and preliminary analysis of multi-channel seismic reflection data, acquired during the oceanographic cruises of the TOMO-ETNA experiment
}

\author{
Marco Firetto Carlino ${ }^{1, \star}$, Fabrizio Zgur ${ }^{2}$, Pier Paolo G. Bruno ${ }^{3}$, Mauro Coltelli ${ }^{1}$, \\ Lorenzo Sormani ${ }^{2}$, Danilo Cavallaro ${ }^{1,4}$, Jesús M. Ibáñez ${ }^{5,1}$, Domenico Patanè ${ }^{1}$ \\ ${ }^{1}$ Istituto Nazionale di Geofisica e Vulcanologia, Sezione di Catania, Osservatorio Etneo, Catania, Italy \\ ${ }^{2}$ Istituto Nazionale di Oceanografia e Geofisica Sperimentale, Sgonico (Trieste), Italy \\ ${ }^{3}$ Petroleum Institute, Department of Petroleum Geosciences, Abu Dhabi, United Arab Emirates \\ ${ }^{4}$ Università di Catania, Dipartimento di Scienze Biologiche, Geologiche e Ambientali, Catania, Italy \\ ${ }^{5}$ Instituto Andaluz de Geofisica, Universidad de Granada, Granada, Spain
}

\author{
Article history \\ Received January 12, 2016; accepted May 30, 2016. \\ Subject classification: \\ Aeolian archipelago, Mt. Etna offshore, Multi-channel seismic data processing, Reflection seismology.
}

\begin{abstract}
The TOMO-ETNA experiment was performed in the framework of the FP7 "MED-SUV" (MEDiterranean SUpersite Volcanoes) in order to gain a detailed geological and structural model of the continental and oceanic crust concerning Etna and Aeolian Islands volcanoes (Sicily, Italy), by means of active and passive seismic exploration methodologies. Among all data collected, some $1410 \mathrm{~km}$ of marine multi-channel seismic (MCS) reflection profiles were acquired in the Ionian and Tyrrhenian Seas during two of the three oceanographic cruises of the TOMO-ETNA experiment, in July and November 2014, with the aim of shading light to deep, intermediate and shallow stratigraphy and crustal structure of the two above mentioned areas. The MCS sections, targeted to deep exploration, were acquired during the oceanographic cruise on board of the $R / V$ "Sarmiento de Gamboa", using an active seismic source of 16 air-guns, for a total volume of $4340 \mathrm{cu}$. in., and a $3000 \mathrm{~m}$ long, 240-channels digital streamer as receiving system. High-resolution seismic profiles were instead collected through the R/V "Aegaeo", using two smaller air-guns (overall $270 \mathrm{cu}$. in. volume) and a 96 channels, $300 \mathrm{~m}$ long digital streamer. This paper provides a detailed description of the acquisition parameters and main processing steps adopted for the MCS data. Some processed lines are shown and preliminarily interpreted, to highlight the overall good quality and the high potential of the MCS sections collected during the TOMO-ETNA experiment.
\end{abstract}

\section{Introduction}

The TOMO-ETNA experiment, which is part of the European Union funded FP7 "MED-SUV” (MEDiterranean SUpersite Volcanoes) project (Ibáñez et al. 2016a, in this volume], aims at better defining the main re- gional tectonic and crustal seismo-stratigraphic pattern of Etna volcano and surroundings, up to north-eastern Sicily, and to contribute for understanding the physical processes controlling magma ascent beneath Etna and Aeolian Island volcanoes.

The geodynamic setting of north and central-eastern Sicily suggests that some shallow and crustal-scale structures, that control the regional seismicity and magma uprising in this region, are located offshore. Although a large number of scientific papers have been written on this area [e.g. Nicolich et al. 2000; Argnani and Bonazzi 2005; Argnani 2009; Argnani et al. 2009, 2012, 2013; Chiocci et al. 2011; Polonia et al. 2011; Gallais et al. 2012, 2013; Argnani 2014; Gross et al. 2016], some geological aspects of this peculiar sector of the Mediterranean are still object of debate, mostly due to lack of adequate resolution in crustal imaging, leading to controversial interpretations.

To overcome the above-mentioned resolution limits, multi-channel marine seismic reflection surveys (MCS) were scheduled during the TOMO-ETNA experiment [see Coltelli et al. 2016, in this volume], with the aim of exploring the subsurface along directions of particular geologic interest, and eventually clarifying the scientific discussion about the presence of structures inferred only on the basis of intuition and low-resolution data.

In the specific, the main topics that inspired our planning were:

- identifying and modeling the Moho discontinu- 


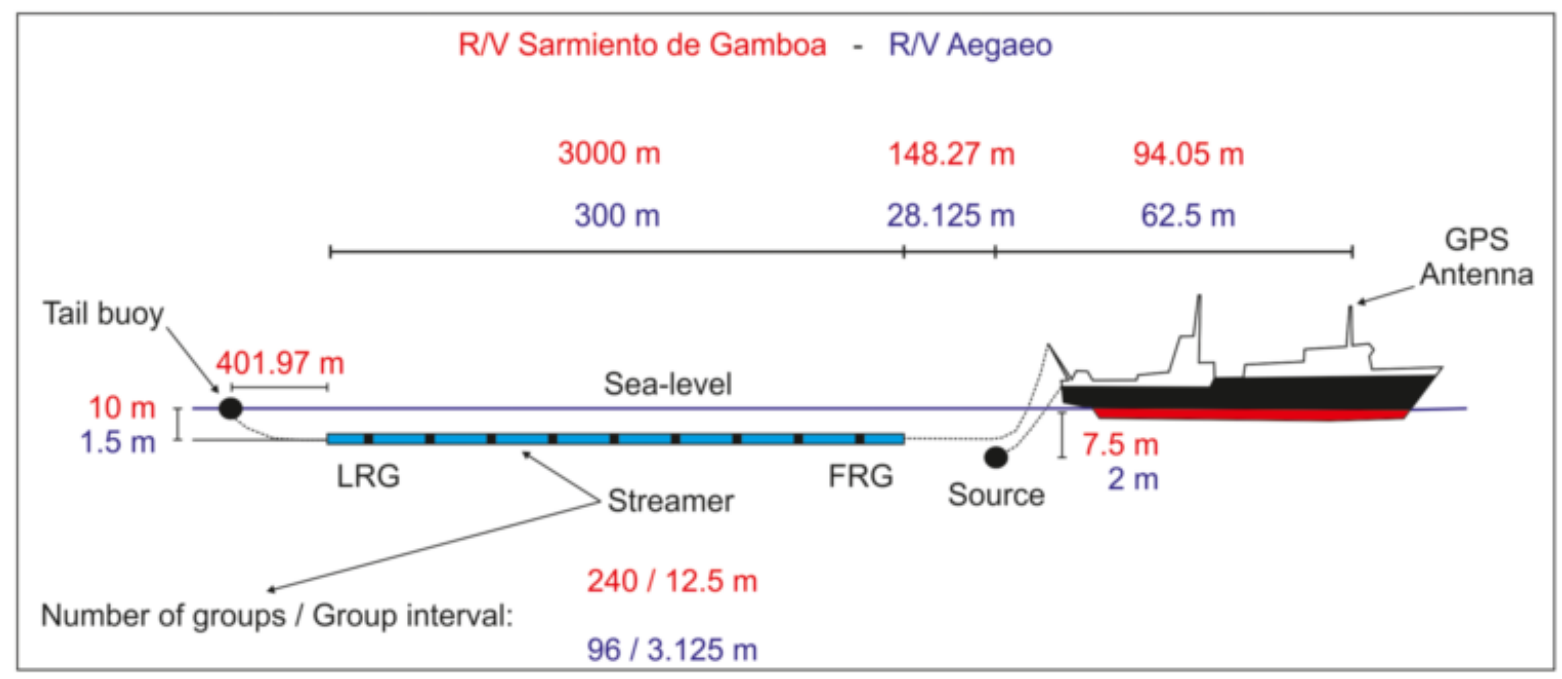

Figure 1. MCS acquisition geometries adopted for the two TOMO-ETNA cruises (red: R/V "Sarmiento de Gamboa"; blue: R/V "Aegaeo"). FRG - First Receiver Group; LRG - Last Receiver Group.

ity in the whole area of interest, comparing the results with Nicolich et al. [2000];

- constraining the main lineaments of the Malta Escarpment fault system [Grasso and Lentini 1982; Grasso et al. 1990; Argnani and Bonazzi 2005], in order to clarify its possible correlation with magmatism at Mt. Etna and its possible role as a seismogenetic source for some of the large earthquakes that in times affected the Ionian sector of Sicily;

- defining the nature of the debated Aeolian-Tindari-Letojanni lineament [Ghisetti 1979; Lanzafame and Bousquet 1997; De Guidi et al. 2013], which is considered as source of significant seismic activity and clarifying its hypothesized correlation with the lithospheric tearing of the Ionian slab;

- clarifying the nature of the bulge located offshore Mt. Etna and whose interpretation is still controversial, [Chiocci et al. 2011; Argnani et al. 2013; Gross et al. 2016], the extension of the structure defined as Timpe volcano [Chiocci et al. 2011; Cavallaro et al. 2016, in this volume] and the presumed occurrence of volcanics on top of the Riposto Ridge [Patanè et al. 2009; Cavallaro et al. 2016, in this volume];

- constraining the deep-seated driving mechanism of the seaward gravitational sliding, affecting the eastern flank of Mt. Etna, object of several previous papers [Borgia et al. 1992, 2000; Chiocci et al. 2011; among others].

At the end of the oceanographic cruises of the TOMO-ETNA experiment, about $1410 \mathrm{~km}$ of MCS profiles were acquired both in the Ionian and in the Tyrrhenian Seas, despite several instrumental issues and logistic problems caused by the presence of longlines fishing along the planned routes, especially during the first cruise (for further details about the oceanographic cruises, as well as for the technical specifications of the seismic equipment employed within the TOMO-ETNA experiment, see Coltelli et al. [2016] in this volume). This paper aims at providing a detailed report of the acquisition parameters, on board quality control and main seismic data-processing stages performed on the TOMO-ETNA MCS survey. It is part of a special volume, which describes in details the whole experiment, the relative data acquisition and processing and some preliminary results.

\section{Surveys and methods}

Although the main goal of the TOMO-ETNA experiment was to achieve a high-resolution tomography through the wide-angle seismic (WAS) technique [Ibáñez et al. 2016a, 2016b, in this volume], MCS data were also collected, to provide not only information about the geometrical pattern of the sub-bottom tectonic structures, but also to infer a $2 \mathrm{D}$ velocity model for each profile. The integration between MCS and WAS methods will strengthen the geological interpretation of the study area, since WAS velocity model can furnish additional information about seismic bodies imaged in the time-sections, and because MCS data will provide higher-resolution images of the subsurface, that can constraint WAS tomography in the overlapping rock volume.

For a proper imaging of both the deep and shallow structural patterns of the investigated area, two different scale and resolution MCS acquisition surveys were planned in the Ionian and Tyrrhenian Seas, through two different oceanographic cruises [Coltelli et al. 2016, in this volume]. In particular, the intent of the cruise performed from June 24 to July 20, 2014, on board of the R/V "Sarmiento de Gamboa" (CSIC-UTM) with the support of the patrol ship "Levanzo" (Italian Navy), was to image in detail the deep crustal structures, possibly down to the Moho discontinuity. Instead, the ob- 
jective of the cruise performed from November 19 to 26, 2014, with the R/V "Aegaeo", was to acquire a highresolution image of the shallow reflectors above the acoustic basement, achieving a good compromise between resolving power and penetration.

Seismic pulses were produced using R/V towed arrays of air-guns [Coltelli et al. 2016, in this volume], whilst seismic signals were recorded by hydrophone cables (steamers; Figure 1). During both cruises, the MCS dataset was recorded as SegD format and logged on the acquisition computer. Navigation logs, mainly containing information about shot-time, vessel's positions (geographic and UTM coordinates) and bearing for every shot, were then exported as text files (ASCII).

\subsection{Deep seismic exploration field parameters}

A total of 25 MCS lines were acquired in the Ionian Sea during the first of the TOMO-ETNA cruises, from July 11 to 17,2014 , for an overall length of some $590 \mathrm{~km}$ (Figure 2 and Table 1).

To image the deep structures of the crust, it was necessary to deliver a large amount of low frequency energy into the water, and to maximize the number of seismic traces in each common mid-point (CMP) gather (CMP fold coverage), in order to improve the signal-to-noise
$(\mathrm{S} / \mathrm{N})$ ratio in the stacked sections [see Yilmaz 2001].

To achieve a good compromise between available instrumentation and expected targets, several simulations were conducted before the cruise, at the Consejo Superior de Investigaciones Científicas (CSIC) in Barcelona, Spain, using the GUNDALF array modeling software, in order to properly design the air-guns arrangement. We chose to use two parallel air-guns arrays of 8 Sercel G-GUN II, each kept at $7.5 \mathrm{~m}$ below sea level (bsl; Figure 1). With this configuration we were able to produce a total volume of $4340 \mathrm{cu}$. in. $(71.12 \mathrm{l})$. The resulting theoretical wavelet was highly energetic at frequencies between 8 and $70 \mathrm{~Hz}$, with the dominant frequency centered around $20 \mathrm{~Hz}$.

The time interval between shots had to be large enough to allow the compressors recharge the air-guns to a nominal pressure of 140 bar, but small enough to ensure the highest possible fold in CMP gathers. The best compromise was found using a time interval of about $20 \mathrm{~s}$, which corresponds to a distance between shotpoints of $37.5 \mathrm{~m}$ at a constant vessel speed of $3.5-3.8 \mathrm{kn}$. The energy released by the air-guns was recorded by a 240channels (with arrays of 8 hydrophones for each channel), 3000-m-long "Sercel-Sentinel" digital streamer, with a $12.5 \mathrm{~m}$ channel distance, corresponding to an ef-

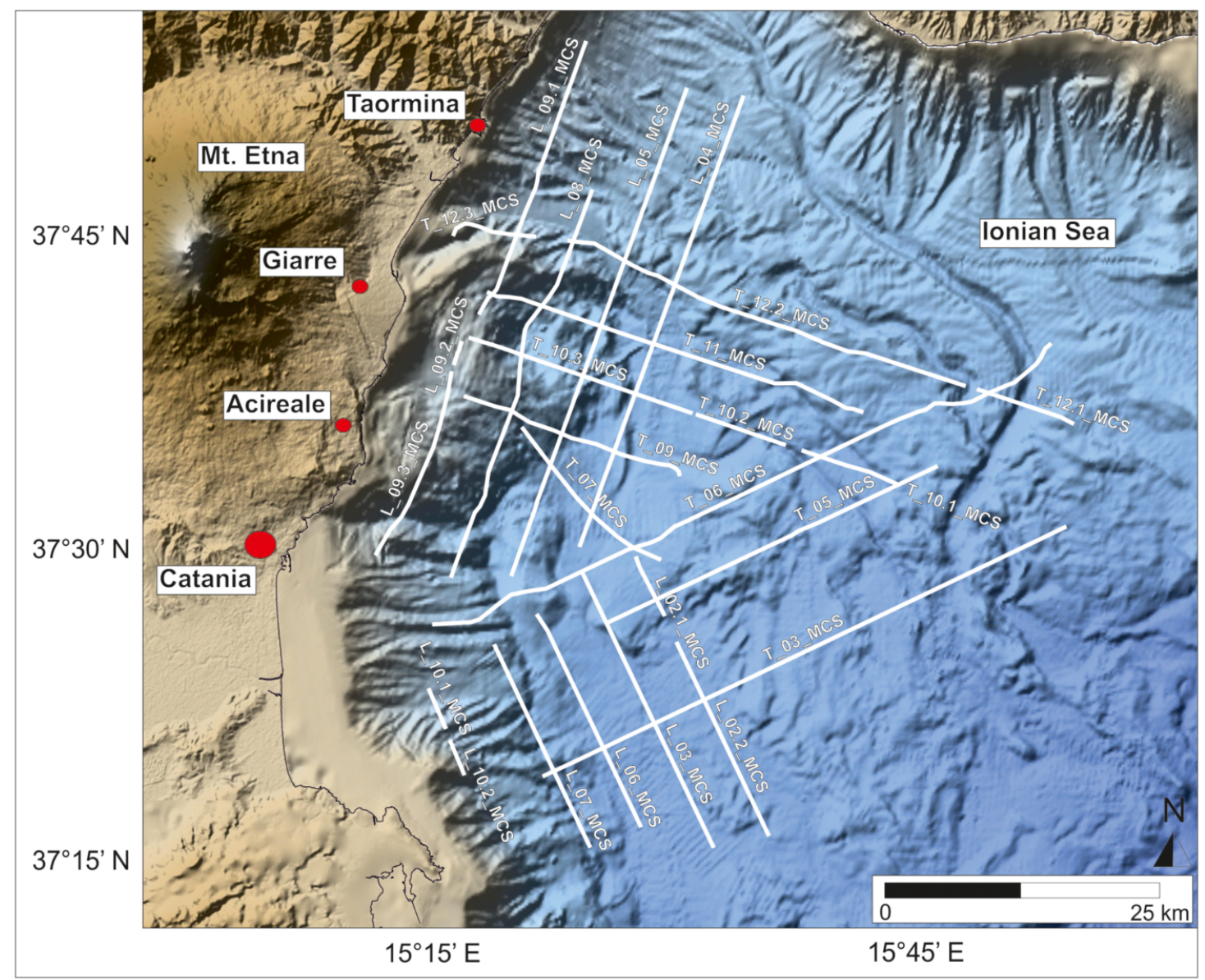

Figure 2. Acquisition map in the Ionian Sea during the TOMO-ETNA cruise on board of the R/V "Sarmiento de Gamboa". 


\begin{tabular}{|c|c|c|c|c|c|c|}
\hline \multirow{2}{*}{$\begin{array}{c}\begin{array}{c}\text { Line } \\
\text { name }\end{array} \\
\text { L_02.1_MCS }\end{array}$} & \multirow{2}{*}{$\begin{array}{c}\begin{array}{c}\text { Number } \\
\text { of shots }\end{array} \\
165\end{array}$} & \multicolumn{2}{|c|}{$\begin{array}{l}\text { Start of line } \\
\qquad(\mathrm{X} \mid \mathrm{Y})\end{array}$} & \multicolumn{2}{|c|}{$\begin{array}{l}\text { End of line } \\
\qquad(\mathrm{X} \mid \mathrm{Y})\end{array}$} & \multirow{2}{*}{$\begin{array}{c}\begin{array}{c}\text { Length } \\
(\mathbf{k m})\end{array} \\
6\end{array}$} \\
\hline & & 540355.52 & 4150297.69 & 542940.64 & 4144884.63 & \\
\hline L_02.2_MCS & 524 & 544122.75 & 4142393.06 & 552240.49 & 4125305.74 & 18.9 \\
\hline L_03_MCS & 440 & 547392.71 & 4123886.17 & 535428.79 & 4148959.35 & 27.8 \\
\hline L_04_MCS & 1184 & 535270.93 & 4151185.48 & 550135.25 & 4192211.07 & 43.7 \\
\hline L_05_MCS & 1275 & 544972.04 & 4192836.30 & 529032.34 & 4148617.30 & 47 \\
\hline L_06_MCS & 587 & 531364.70 & 4144911.55 & 540716.12 & 4125824.73 & 21.3 \\
\hline L_07_MCS & 562 & 536157.58 & 4123840.64 & 527552.48 & 4142086.89 & 20.2 \\
\hline L_08_MCS & 986 & 523506.10 & 4148416.01 & 536316.01 & 4183582.32 & 37.9 \\
\hline L_09.1_MCS & 735 & 535786.30 & 4197078.47 & 526138.65 & 4172480.69 & 26.6 \\
\hline L_09.2_MCS & 54 & 524444.65 & 4169697.89 & 523815.51 & 4167852.80 & 2 \\
\hline L_09.3_MCS & 461 & 523546.51 & 4166950.46 & 516613.08 & 4150427.95 & 18.1 \\
\hline T_05_MCS & 914 & 537747.32 & 4144239.86 & 567709.81 & 4158425.06 & 33.2 \\
\hline T_06_MCS & 1729 & 578139.36 & 4169631.69 & 521839.53 & 4144103.63 & 63.1 \\
\hline L_10.1_MCS & 68 & 521502.22 & 4138125.04 & 522976.34 & 4134700.41 & 3.7 \\
\hline L_10.2_MCS & 67 & 523532.69 & 4133379.66 & 524675.51 & 4130480.61 & 3.1 \\
\hline T_03_MCS & 1218 & 531870.07 & 4130285.42 & 579527.85 & 4152944.48 & 52.8 \\
\hline T_12.1_MCS & 253 & 580177.7 & 4162409.91 & 571572.88 & 4165418.31 & 9.1 \\
\hline T_12.2_MCS & 1040 & 570330.79 & 4165817.83 & 534152.38 & 4179066.79 & 38.8 \\
\hline T_12.3_MCS & 228 & 531176.13 & 4179422.92 & 523737.57 & 4179472.31 & 8.2 \\
\hline T_11_MCS & 997 & 526868.96 & 4174351.93 & 561017.74 & 4163390.89 & 36.1 \\
\hline T_10.1_MCS & 235 & 564325.22 & 4156839.34 & 555671.18 & 4159869.72 & 9.2 \\
\hline T_10.2_MCS & 242 & 553909.16 & 4160470.10 & 545851.52 & 4163209.69 & 8.5 \\
\hline T_10.3_MCS & 506 & 545429.54 & 4163349.23 & 525209.95 & 4170185.53 & 21.4 \\
\hline T_09_MCS & 531 & 524785.71 & 4164920.5 & 544322.66 & 4157639.60 & 21.2 \\
\hline \multirow[t]{3}{*}{ T_07_MCS } & 362 & 542575.21 & 4149965.16 & 530025.67 & 4162033.59 & 17.7 \\
\hline & Total & & & & & Total \\
\hline & 15,363 & & & & & 589.6 \\
\hline
\end{tabular}

Table 1. Main characteristics of MCS lines acquired in the Ionian Sea area, during the TOMO-ETNA oceanographic cruise with the R/V "Sarmiento de Gamboa". The coordinate are projected in UTM-WGS84, zone 33N.

fective horizontal CMP sampling of $6.25 \mathrm{~m}$ in the stacked sections. Streamer was kept at a constant depth of about $10 \mathrm{~m}$ bsl by means of a set of levelers (known as birds); the corresponding notch frequency related to the ghost effect was $75 \mathrm{~Hz}$ [Badley 1985; Yilmaz 2001]. The distance between the source centroid and the first channel (near offset) depends on the length of the tow leader and was set to $148.27 \mathrm{~m}$ (Figure 1). To receive deep reflections, record length was set at $19 \mathrm{~s}$ with a sampling rate of $2 \mathrm{~ms}$, yielding a Nyquist temporal frequency of $250 \mathrm{~Hz}$. Source and geophone spacing allowed a theoretical maximum fold coverage of 40 traces/CMP.
2.2. Mid-shallow seismic exploration field parameters

A total of 36 MCS lines were acquired in the Tyrrhenian Sea (Figure 3, top, and Table 2) and 15 in the Ionian Sea (Figure 3, bottom, and Table 3) during the third of the TOMO-ETNA cruises, from November 19 to 26, 2014, for a total length of about $818 \mathrm{~km}$.

For this dataset, our priority was to obtain a broad frequency content of the seismic pulse, rather than high energy content. Therefore, the seismic source was scaled to a $2 \mathrm{~m}$ long linear air-guns array formed by one $210 \mathrm{cu}$. in. Sercel GI-GUN and one $60 \mathrm{cu}$. in. Sercel Mini GI-GUN (for a total volume of 4.431 ) hung on a steel beam and kept at $2 \mathrm{~m}$ bsl (Figure 1). The frequency bandwidth of 


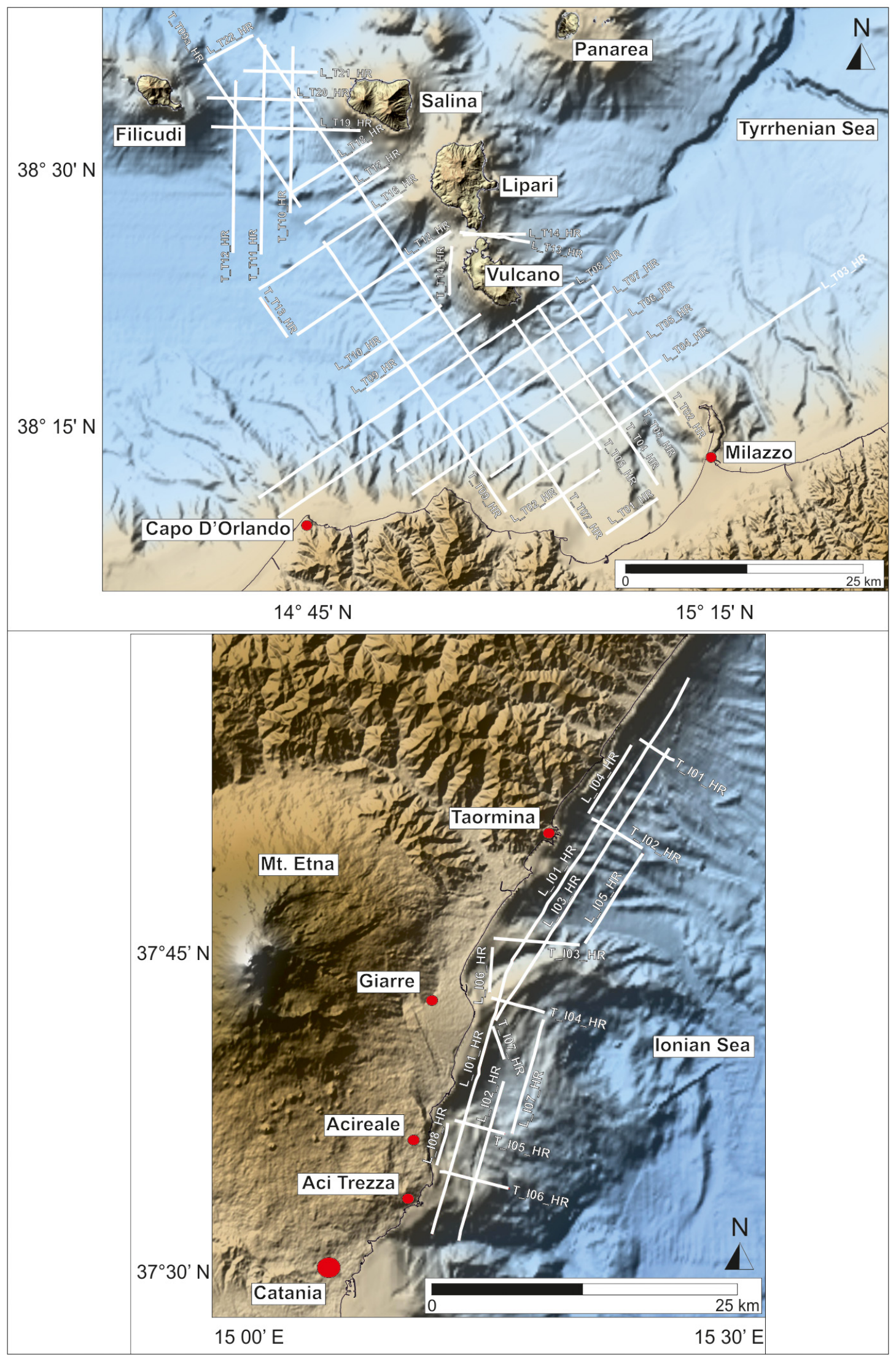

Figure 3. Acquisition map in the Tyrrhenian (top) and Ionian (bottom) Seas during the TOMO-ETNA experiment with R/V "Aegaeo".

the recorded signal was quite broad, i.e. between 20 $280 \mathrm{~Hz}$ (Figure 4). Considering P-wave velocities ranging from 1520 to $4000 \mathrm{~m} / \mathrm{s}$, and a dominant frequency of $\sim 125 \mathrm{~Hz}$, according to the $\lambda / 4$ Rayleigh criterion, a resolving power (i.e. vertical resolution) ranging between 3 and $8 \mathrm{~m}$ was expected in the acquired data.

Due to the air compressor limits, the shot interval was necessarily set to $12-13$ seconds (i.e. $\sim 22 \mathrm{~m}$ shot 


\begin{tabular}{|c|c|c|c|c|c|c|}
\hline \multirow{2}{*}{$\begin{array}{c}\begin{array}{c}\text { Line } \\
\text { name }\end{array} \\
\text { L_T18_HR }\end{array}$} & \multirow{2}{*}{$\begin{array}{c}\begin{array}{c}\text { Number } \\
\text { of shots }\end{array} \\
655\end{array}$} & \multicolumn{2}{|c|}{$\begin{array}{l}\text { Start of line } \\
\qquad(\mathrm{X} \mid \mathrm{Y})\end{array}$} & \multicolumn{2}{|c|}{$\begin{array}{l}\text { End of line } \\
\qquad(X \mid Y)\end{array}$} & \multirow{2}{*}{$\begin{array}{c}\begin{array}{c}\text { Length } \\
(\mathbf{k m})\end{array} \\
10.2\end{array}$} \\
\hline & & 476283.50 & 4258476.02 & 484849.62 & 4263938.65 & \\
\hline L_T19_HR & 722 & 483625.29 & 4265149.80 & 467899.09 & 4265583.86 & 15.7 \\
\hline L_T20_HR & 519 & 467375.98 & 4268572.62 & 478670.58 & 4268328.89 & 11.3 \\
\hline L_T21_HR & 358 & 479077.77 & 4271358.68 & 471298.49 & 4271493.25 & 7.8 \\
\hline T_T12_HR & 836 & 470519.83 & 4270387.64 & 470148.94 & 4252213.81 & 18.2 \\
\hline T_T11_HR & 1020 & 473135.85 & 4252047.02 & 473529.59 & 4274258.15 & 22.2 \\
\hline T_T10_HR & 804 & 476556.07 & 4273988.43 & 476199.66 & 4256456.59 & 17.5 \\
\hline L_T17_HR & 486 & 477807.96 & 4255249.23 & 486574.18 & 4261192.83 & 10.6 \\
\hline L_T16_HR & 831 & 488090.82 & 4258231.77 & 472924.67 & 4248309.27 & 18.1 \\
\hline T_T13_HR & 238 & 473023.32 & 4247449.76 & 475920.18 & 4243172.22 & 5.2 \\
\hline L_T12_HR & 897 & 476976.44 & 4243483.38 & 493237.77 & 4254375.18 & 19.6 \\
\hline L_T13_HR & 344 & 494233.05 & 4254330.18 & 501620.87 & 4253294.35 & 7.5 \\
\hline L_T14_HR & 307 & 501224.81 & 4254141.29 & 494552.64 & 4254076.77 & 6.7 \\
\hline T_T14_HR & 240 & 493435.39 & 4252843.88 & 493071.13 & 4247649.70 & 5.2 \\
\hline L_T10_HR & 541 & 492276.18 & 4246556.23 & 482585.14 & 4239843.49 & 11.8 \\
\hline L_T09_HR & 667 & 484335.58 & 4237525.56 & 496423.45 & 4245635.33 & 14.6 \\
\hline T_T05_HR & 758 & 499907.43 & 4245006.88 & 509229.36 & 4231341.86 & 16.5 \\
\hline L_T02_HR & 402 & 509072.03 & 4229114.54 & 501817.44 & 4224198.39 & 8.8 \\
\hline T_T09_HR & 1586 & 499117.60 & 4224655.51 & 479755.99 & 4253344.53 & 34.6 \\
\hline T_T09A_HR & 841 & 499117.60 & 4224655.51 & 467096.90 & 4272253.69 & 57.4 \\
\hline L_T22_HR & 254 & 467403.75 & 4272606.49 & 472257.55 & 4275238.89 & 5.5 \\
\hline T_T07_HR & 2901 & 472756.73 & 4274915.08 & 507978.61 & 4222268.14 & 63.4 \\
\hline L_T01_HR & 302 & 509784.89 & 4222322.47 & 515214.95 & 4226039.53 & 6.6 \\
\hline T_T04_HR & 1044 & 515232.12 & 4227602.66 & 502488.94 & 4246499.32 & 22.8 \\
\hline T_T03_HR & 215 & 505143.14 & 4247977.88 & 507767.84 & 4244126.33 & 4.7 \\
\hline T_T03A_HR & 88 & 507975.99 & 4243846.04 & 508969.58 & 4242225.56 & 1.9 \\
\hline T_T03B_HR & 159 & 507536.68 & 4244410.28 & 509488.91 & 4241565.55 & 3.5 \\
\hline T_T03C_HR & 92 & 510109.08 & 4240594.81 & 511188.08 & 4238932.83 & 2.0 \\
\hline T_T03D_HR & 97 & 511479.88 & 4238539.93 & 512664.46 & 4236808.53 & 2.1 \\
\hline T_T02_HR & 759 & 517481.43 & 4234937.51 & 508311.45 & 4248723.02 & 16.6 \\
\hline L_T08_HR & 1853 & 506335.28 & 4248899.45 & 472881.22 & 4226143.48 & 40.5 \\
\hline L_T07_HR & 1954 & 474986.15 & 4224075.40 & 510327.74 & 4247976.37 & 42.7 \\
\hline L_T06_HR & 1353 & 511937.05 & 4245481.70 & 487488.33 & 4228920.91 & 29.5 \\
\hline L_T05_HR & 1360 & 489249.42 & 4226520.29 & 513851.98 & 4243147.70 & 29.7 \\
\hline L_T04_HR & 1002 & 515568.23 & 4240721.78 & 497541.68 & 4228367.92 & 21.9 \\
\hline \multirow[t]{3}{*}{ L_T03_HR } & 1817 & 499526.50 & 4226170.86 & 532404.85 & 4248359.47 & 39.7 \\
\hline & Total & & & & & Total \\
\hline & 28,302 & & & & & 652.6 \\
\hline
\end{tabular}

Table 2. Main characteristics of MCS lines acquired in the Tyrrhenian Sea area, during the TOMO-ETNA oceanographic cruise with the $\mathrm{R} / \mathrm{V}$ "Aegaeo". The coordinate are projected in UTM-WGS84, zone 33N. 


\begin{tabular}{|c|c|c|c|c|c|c|}
\hline \multirow{2}{*}{$\begin{array}{c}\begin{array}{c}\text { Line } \\
\text { name }\end{array} \\
\text { L_I01_HR }\end{array}$} & \multirow{2}{*}{$\begin{array}{c}\begin{array}{c}\text { Number } \\
\text { of shots }\end{array} \\
2491\end{array}$} & \multicolumn{2}{|c|}{$\begin{array}{l}\text { Start of line } \\
\qquad(\mathrm{X} \mid \mathrm{Y})\end{array}$} & \multicolumn{2}{|c|}{$\begin{array}{l}\text { End of line } \\
\qquad(X \mid Y)\end{array}$} & \multirow{2}{*}{$\begin{array}{c}\begin{array}{c}\text { Length } \\
(\mathbf{k m})\end{array} \\
54.3\end{array}$} \\
\hline & & 538114.87 & 4203189.75 & 515626.28 & 4154453.65 & \\
\hline L_I02_HR & 663 & 517933.56 & 4153894.72 & 521879.56 & 4167769.24 & 14.4 \\
\hline T_I07_HR & 135 & 521918.45 & 4169830.60 & 520956.28 & 4172588.57 & 2.9 \\
\hline L_I03_HR & 1294 & 521206.95 & 4173201.31 & 536373.48 & 4196969.26 & 28.2 \\
\hline T_I01_HR & 157 & 536745.74 & 4196026.55 & 533860.63 & 4197832.06 & 3.4 \\
\hline L_I04_HR & 319 & 533085.89 & 4197278.93 & 529401.30 & 4191398.28 & 6.9 \\
\hline T_I02_HR & 230 & 529677.41 & 4190850.20 & 533992.44 & 4188330.97 & 5.0 \\
\hline L_I05_HR & 426 & 534126.41 & 4187807.81 & 529103.58 & 4180021.44 & 9.3 \\
\hline T_I03_HR & 341 & 528502.93 & 4179796.04 & 521104.54 & 4180355.04 & 7.4 \\
\hline L_I06_HR & 180 & 520950.45 & 4179553.62 & 520652.38 & 4175662.48 & 3.9 \\
\hline T_I04_HR & 215 & 520891.33 & 4175104.84 & 525402.01 & 4173901.91 & 4.7 \\
\hline L_I07_HR & 474 & 525408.24 & 4173209.42 & 522641.73 & 4163278.72 & 10.3 \\
\hline T_I05_HR & 205 & 521918.24 & 4163228.11 & 517620.66 & 4164407.86 & 4.5 \\
\hline L_I08_HR & 174 & 516999.46 & 4164139.95 & 516045.31 & 4160502.40 & 3.8 \\
\hline \multirow[t]{3}{*}{ T_I06_HR } & 285 & 516341.04 & 4159907.62 & 522343.91 & 4158434.95 & 6.2 \\
\hline & Total & & & & & Total \\
\hline & 7589 & & & & & 165.2 \\
\hline
\end{tabular}

Table 3. Main characteristics of MCS lines acquired in the Ionian Sea area, during the TOMO-ETNA oceanographic cruise with the R/V "Aegaeo". The coordinate are projected in UTM-WGS84, zone 33N.

spacing at a cruising speed of $3.5-3.8 \mathrm{kn})$. The receiving system in this case consisted of a $300 \mathrm{~m}$-long, 96-channel "Geometrics GeoEel" digital streamer with $3.12 \mathrm{~m}$ channel spacing, each channel made of an array of 4 hydrophones. The streamer was towed at a depth of $1.5 \mathrm{~m}$ bsl. Source moveout and channel spacing yielded a horizontal CMP sampling of $\sim 1.56 \mathrm{~m}$, and a maximum fold coverage of only $700 \%$ (i.e. 7 traces/CMP). The source near offset was set at $28.125 \mathrm{~m}$ (Figure 1). The record length was set at $5 \mathrm{~s}$, since it is very unlike to record deeper reflected events with this source-receiver configuration, and the digital sampling rate at $1 \mathrm{~ms}$, corresponding to a $500 \mathrm{~Hz}$ Nyquist frequency, well above the data frequency content.

\section{Seismic reflection data processing}

Quality control (QC) and basic processing operations of MCS data began on board, during acquisition. An overall check of the incoming data was performed both in the shot domain (Figure 4) by displaying each single shot being recorded, and in single-channel domain (Figure 5), by displaying all the traces progressively registered by a single channel (common-offset section). Seismic data were then processed in lab to achieve the final seismic stacks. In the next paragraphs it follows a detailed description of the MCS data analy- sis, using examples from both deep and mid-shallow seismic exploration.

\subsection{On board quality control}

During both cruises, a real-time on board QC was dedicated to the identification of problems connected with the acquisition of MCS data, in terms of instrumental and signal-related issues. The QC activity mainly focused on:

- identification of noise affecting the signal and its possible sources (environmental, electric, mechanic, etc.), its nature (random or coherent) and characteristics (such as dominant frequency, apparent velocity and wavelength) with the aim of finding a strategy to reduce its effects;

- ongoing verification of the acquisition parameters and, in particular, quality check of the source's signature in terms of amplitude spectrum and energy (penetration).

Figure 4 shows a single shot of the T_T05_HR line, recorded in the Tyrrhenian Sea during the R/V "Aegaeo" cruise. It is clearly observable an amplitude decay of the reflected wave arrivals, due to both spherical divergence and absorption. In particular, from the top to the bottom of this shot it is possible to observe:

- direct wave arrival: due to the energy propagating 


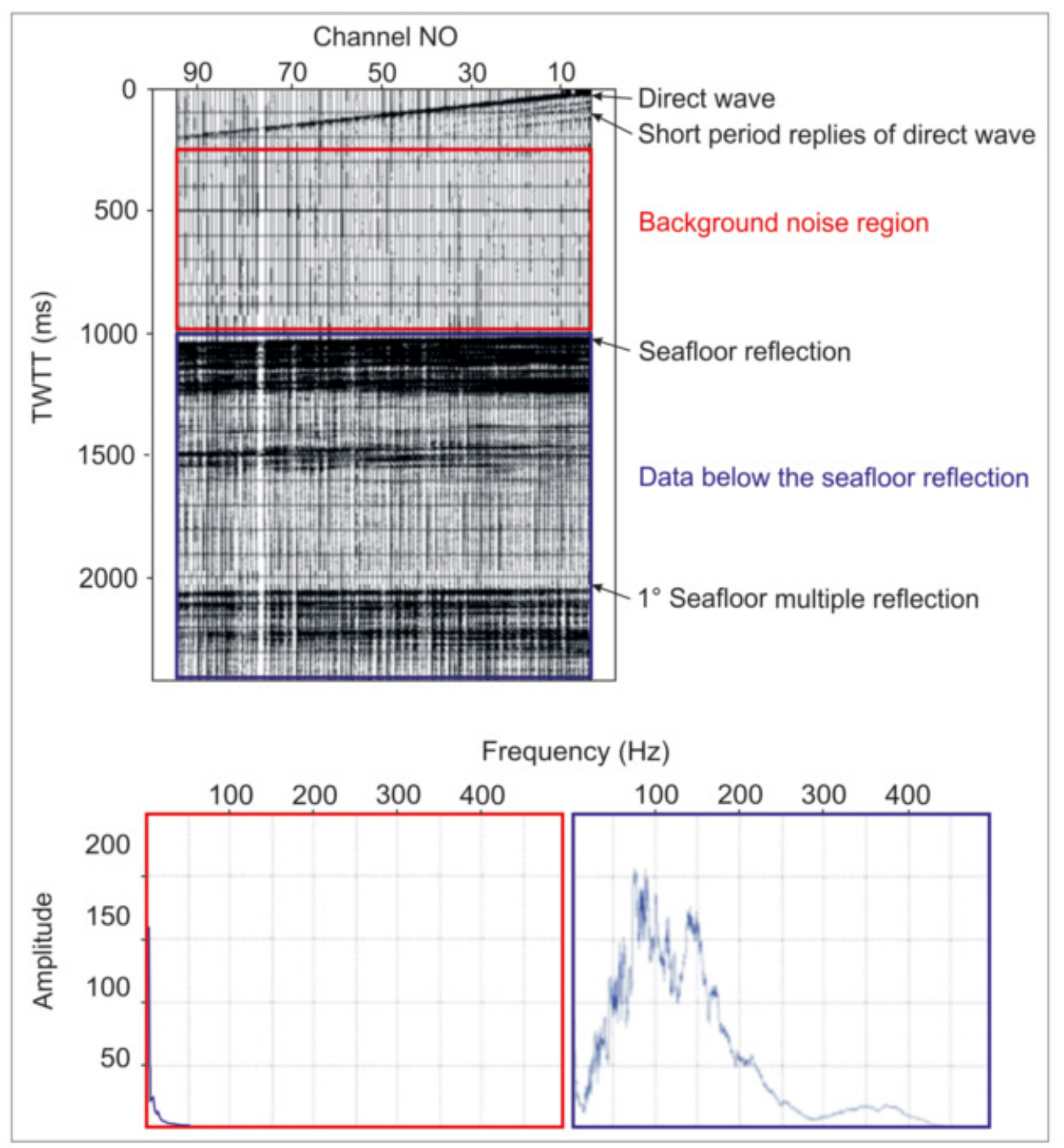

Figure 4. Example of raw data record (common-shot, on the top) of the line T_T05_HR, Tyrrhenian Sea). The main events are highlighted at the right side of the record. At the bottom: the background noise amplitude spectrum (red frame in the record) on the left and the reflected data region amplitude spectrum (blue frame in the record) on the right.

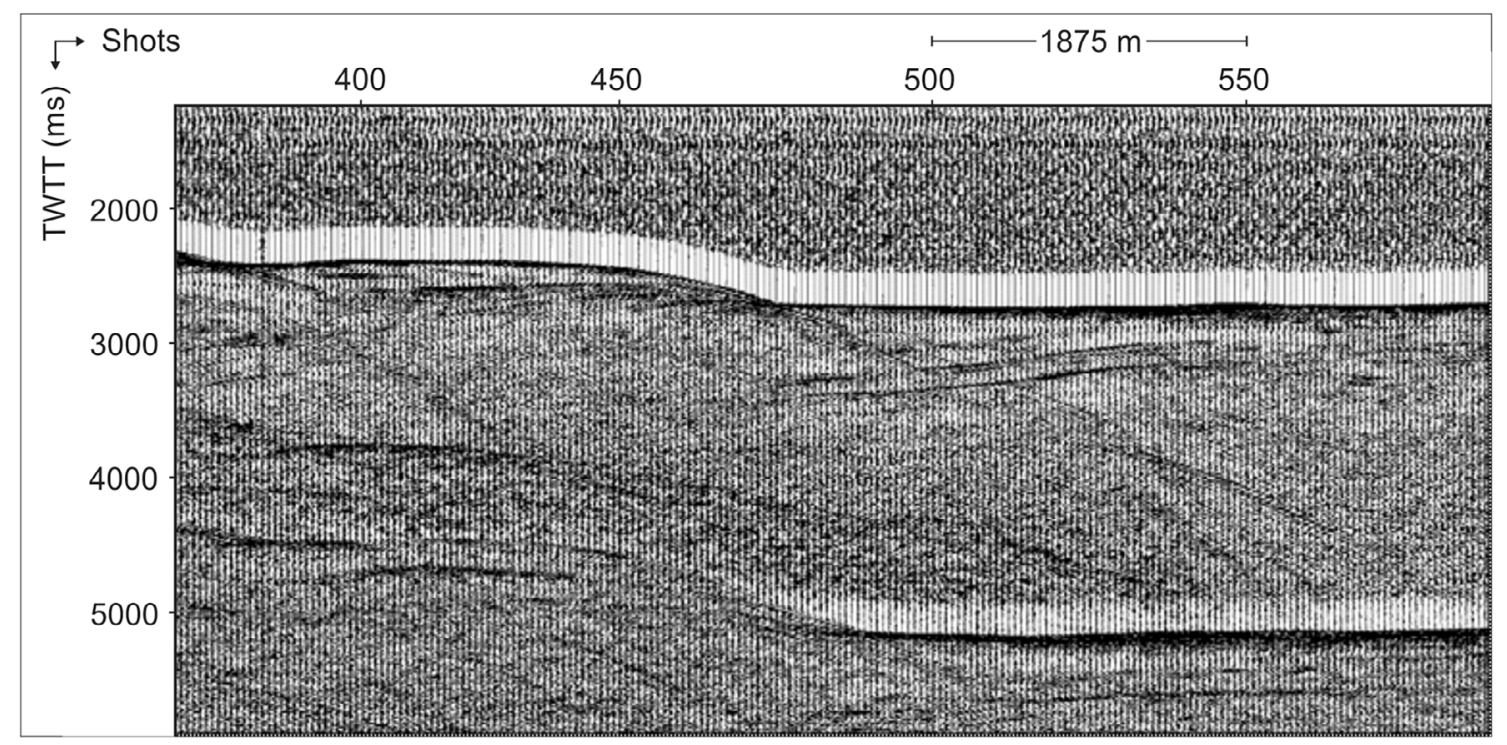

Figure 5. Common-offset trace display of a seismic line acquired during the R/V "Sarmiento de Gamboa" cruise. To get a preliminary view of the data quality, it is common practice to display a single-channel section composed of individual traces extracted shot by shot from the whole dataset. The section shown here (line T_11_MCS, Ionian Sea) is composed by the 100th of 240 traces only. The distance between traces is the same as the shot point interval $(37.5 \mathrm{~m})$. 
directly from the source to the hydrophones, arranged along a straight line in the offset vs two-way travel time (TWTT) domain. From the direct wave it was possible to check on board the velocity of P-waves in shallow water (the inverse of the straight line slope), to verify the near offset and to check the signal quality (see for instance the series of short period replies produced by successive bubble oscillations in Figure 4, top);

background noise: the record is affected by a random, low frequency and high amplitude noise (Figure 4 , red box); its origin is probably related to the acquisition system;

- seafloor reflection: is the energy reflected by the sea bottom at around $1 \mathrm{~s}$ TWTT; being the streamer short with respect to water depth, this event appears as nearly horizontal instead of hyperbolic, as we sample only a short range of offsets;

- seafloor 1st multiple reflection: a reply of the seabottom reflector, having the same shape and frequency content and, since the energy does not rapidly decay in water, an amplitude much higher than that of the primary events (i.e. seismic signals from reflective surfaces) registered at the same time. Seafloor multiples therefore mask the primary reflections and, that is why, one the most important processing stages is targeted to their attenuation;

- data below the seafloor reflection (Figure 4, blue box): containing a time series which represents the crustal reflectivity; they must be enhanced by attenuating all noise through several processing procedures, as it will be illustrated in the next paragraphs.

During QC a spectral analysis was performed in selected time windows: on the background noise region and on the data below the seafloor reflection. The background noise amplitude spectrum (Figure 4, bottom left) exhibits a rapidly decaying of the low frequency and high amplitude component in the spectrogram. The amplitude spectrum of the data below the seafloor reflection (Figure 4, bottom right) has two peaks at 80 and $140 \mathrm{~Hz}$, with some components overlapping the low frequency noise spectrum. A clear notch-related ghost effect is not evident, because the GI-GUN and Mini GI-GUN have actually been kept at different depth: $2 \mathrm{~m}$ (with a theoretical notch at $375 \mathrm{~Hz}$ ) the first and $1.6 \mathrm{~m}$ (theoretical notch at $468 \mathrm{~Hz}$ ) the second. To reduce the random noise a simple band-pass filter was applied.

Figure 5 shows a common-offset gather of the line T_11_MCS, acquired in the Ionian Sea during the R/V "Sarmiento de Gamboa" cruise. A very basic processing, such as gain function and band-pass filtering, was applied to better display the seismic sections, to assist the operator during data QC.

QC also aimed at verifying the match between the number of shots in the navigation files and in the recorded SegDs, since field geometry assignment is a basic step in processing flow. During the R/V "Aegaeo" cruise, it was possible to access both $\mathrm{SegD}$ and navigation files, so that eventual misfits were corrected in real-time. Moreover, some basic processing steps were carried out on board, leading to display preliminary seismic sections, useful to further QC of the acquired data quality.

During the cruise on board of the R/V "Sarmiento de Gamboa", it was not possible to process data, there-

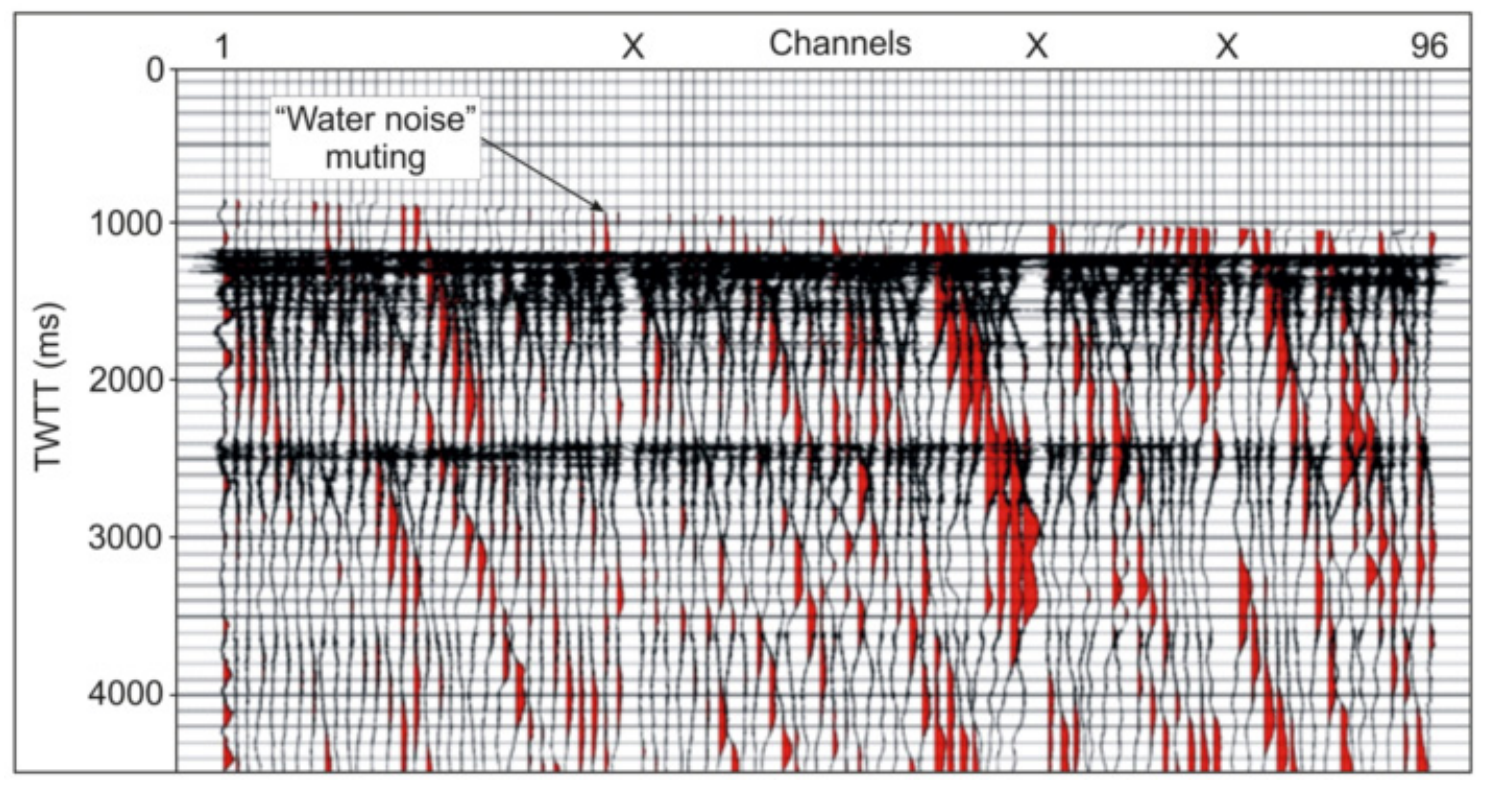

Figure 6. Water noise and noisy trace muting. In this example a raw records of the L_I02_HR is displayed with the water-column noise and the 33th, 65th and 80th traces muted (X). 
fore, QC activities were carried out lately in laboratory, at the Istituto Nazionale di Geofisica e Vulcanologia (INGV)-Osservatorio Etneo. In some MCS profiles many random misfits were detected; the number of shots in the navigation files sometimes exceeded by more than $20 \%$ (over $40 \%$ in one case) the number of registered SegDs. By comparing the acquisition times in both the formats, it was possible to correctly associate every SegD to its real navigation parameters.

3.2. Main steps of multi-channel seismic data processing In this paragraph we report a brief description of the main processing methods applied on MCS data, by using the Schlumberger VISTA. Processing was performed in the common source (CS) or CMP and CMP stack (STK) domains. For further and detailed information about the described processing methods see Yilmaz [2001] or Stain and Wysession [2003].

\section{Water noise and noisy trace muting (CS)}

After the SegD data were converted and imported into the format recognized by the software Schlumberger VISTA and the field geometry was assigned, we performed an analysis of every single shot gather to mute the noise recorded during the time span between the air-gun shot and the primary bottom reflection arrival. Generally, no additional mute of coherent noise was necessary. Extremely noisy traces, that could compromise the overall quality of the final stack, were removed as well (Figure 6).

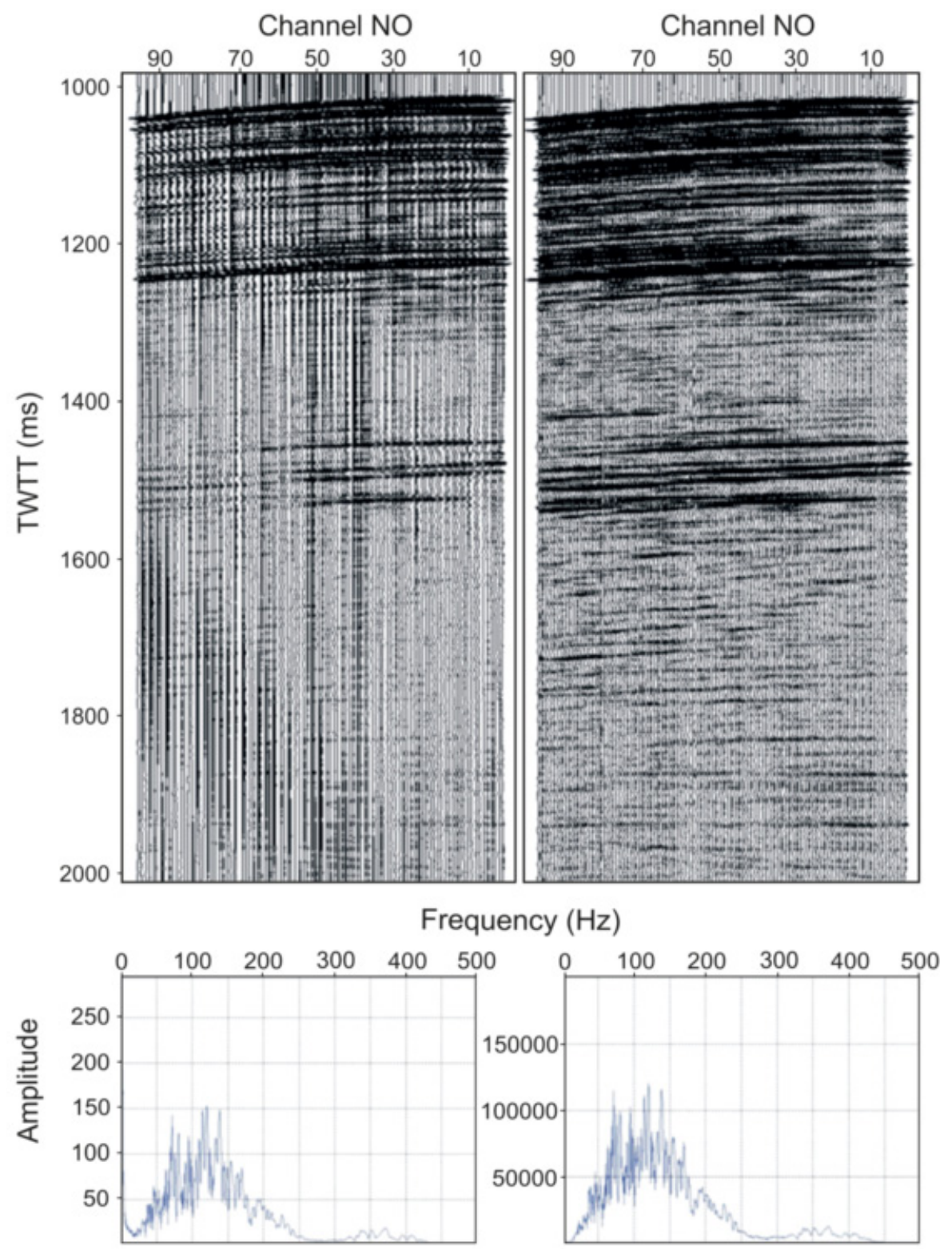

Figure 7. Comparison between raw (left) and filtered (right) shot record (shot point 370, line T_T05_HR) in the time (above) and in the frequency (below) domains. After the application of a band-pass filter and a gain function, it is possible to detect the deeper reflectors and to appreciate that the low frequency noise component (between 0 and $10 \mathrm{~Hz}$ ) has been removed from the spectrum. However, the spectra absolute values are not directly comparable because a gain function is present in the pre-processed version. 
Bandpass filtering and amplitude recovery (CS)

A wide band-pass filter (Ormsby - low cut 8/16 - high cut $300 / 500$ for the mid-shallow and $3 / 6-150 / 250$ for the deep seismic data) was applied to attenuate the unwanted low and the high frequency noise from the data. In the example of Figure 7, a comparison between a raw record (left) and a filtered record (right) is shown. Prior to the filter and gain applications, the record appears to be dominated by a very low frequency and high amplitude noise component $(<10 \mathrm{~Hz})$. This low frequency noise was probably generated by the vessel's engines. After the filter application, these problems were strongly attenuated. An amplitude recovery function was also applied to the data in order to compensate for spherical divergence and absorption. A scaling factor (with a factor 2) and a time-dependent amplitude recovery function in an exponential time power form $\left(\mathrm{T}^{\mathrm{n}}\right.$, being $\mathrm{T}=$ TWTT and $\mathrm{n}=1.6$ ) were applied to all traces. At this stage, a first evaluation of the penetration is already possible. See for example the reflectors between 1.5 and $2 \mathrm{~s}$ in Figure 7 (right), which were barely detectable in the raw version (left).

\section{Spiking deconvolution (CS)}

Under the assumptions of $i$ ) a layered crust with horizontal and constant velocity layers; ii) normal in- cidence and stationarity of the seismic pulse; iii) noisefree data, seismograms can be modeled as the convolution between the source pulse (commonly named wavelet; Badley [1985], Stain and Wysession [2003]) and a time series representing the sequence of the Earth reflection coefficients. When the recorded time between two successive reflectors is shorter than the duration of the seismic pulse, interference takes place. Using the above mentioned assumptions, an inverse filter operator can be estimated from the recorded data, such that its convolution with the recorded seismograms yields an estimate of Earth reflectivity. For unknown source functions, the filter operator must be statistically estimated through the Wiener-Levinson least-squares algorithm, using the first transient of the autocorrelation lags of the seismic traces (Figure 8; see Yilmaz [2001] and references therein). Average operator lengths of $\sim 380 \mathrm{~ms}$ were used for the deep (Figure 8 ) and of $\sim 30 \mathrm{~ms}$ for the HR MCS data (Figure 9). Convolution of the estimated filter operator with our seismograms was successful in spiking the reflections, therefore improving vertical resolution (see the sharpener arrivals on the deconvolved seismograms in Figure 8 ) and in attenuating some reverberations (see for instance the reflected event at $1540 \mathrm{~ms}$ TWTT in Figure 9).

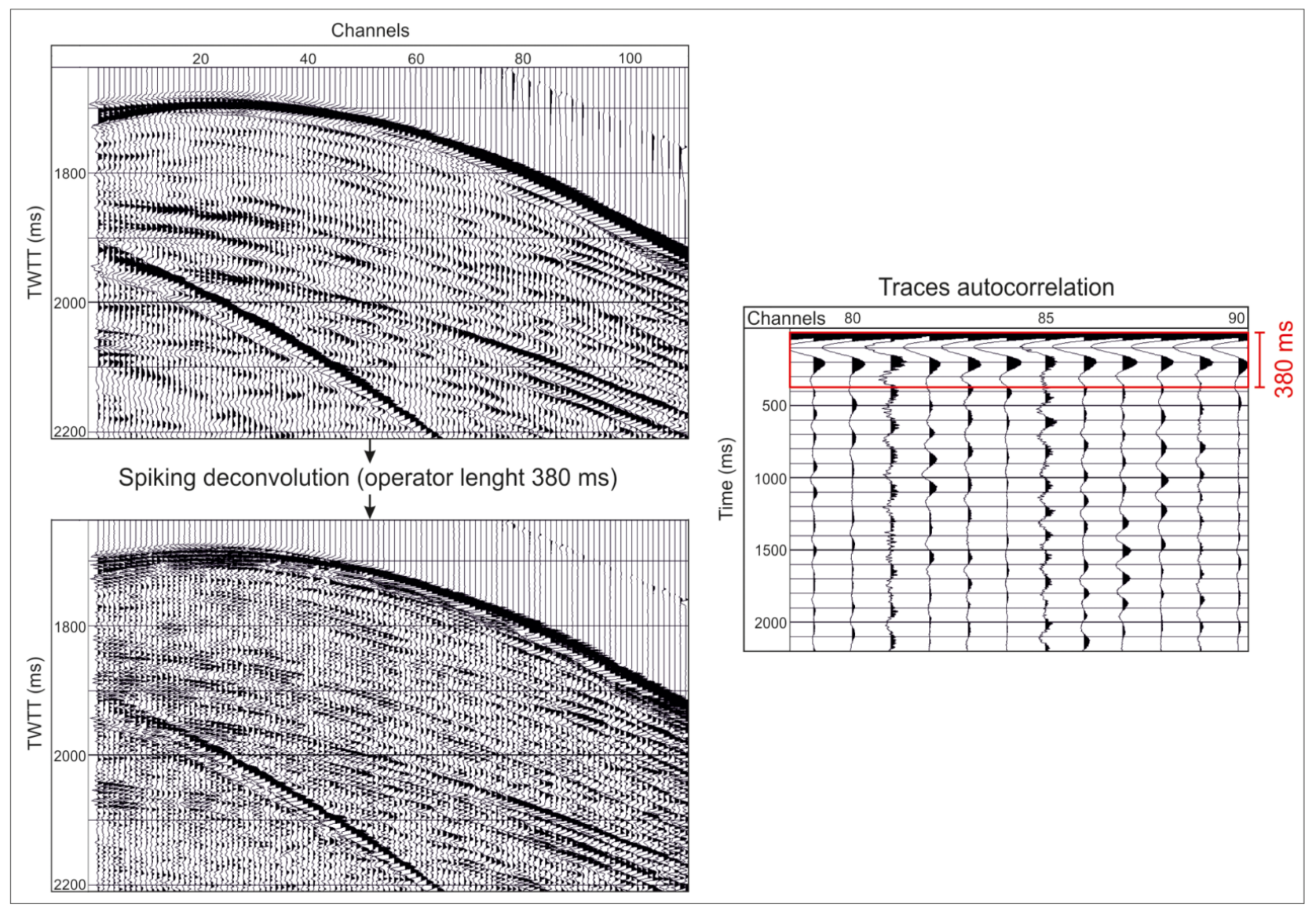

Figure 8. Effects of spiking deconvolution (bottom) on one pre-processed shot (top) of the line L_08_MCS (Ionian Sea), using an operator length of $380 \mathrm{~ms}$. Note the sharpen arrivals of the main reflectors (see text for further details). 


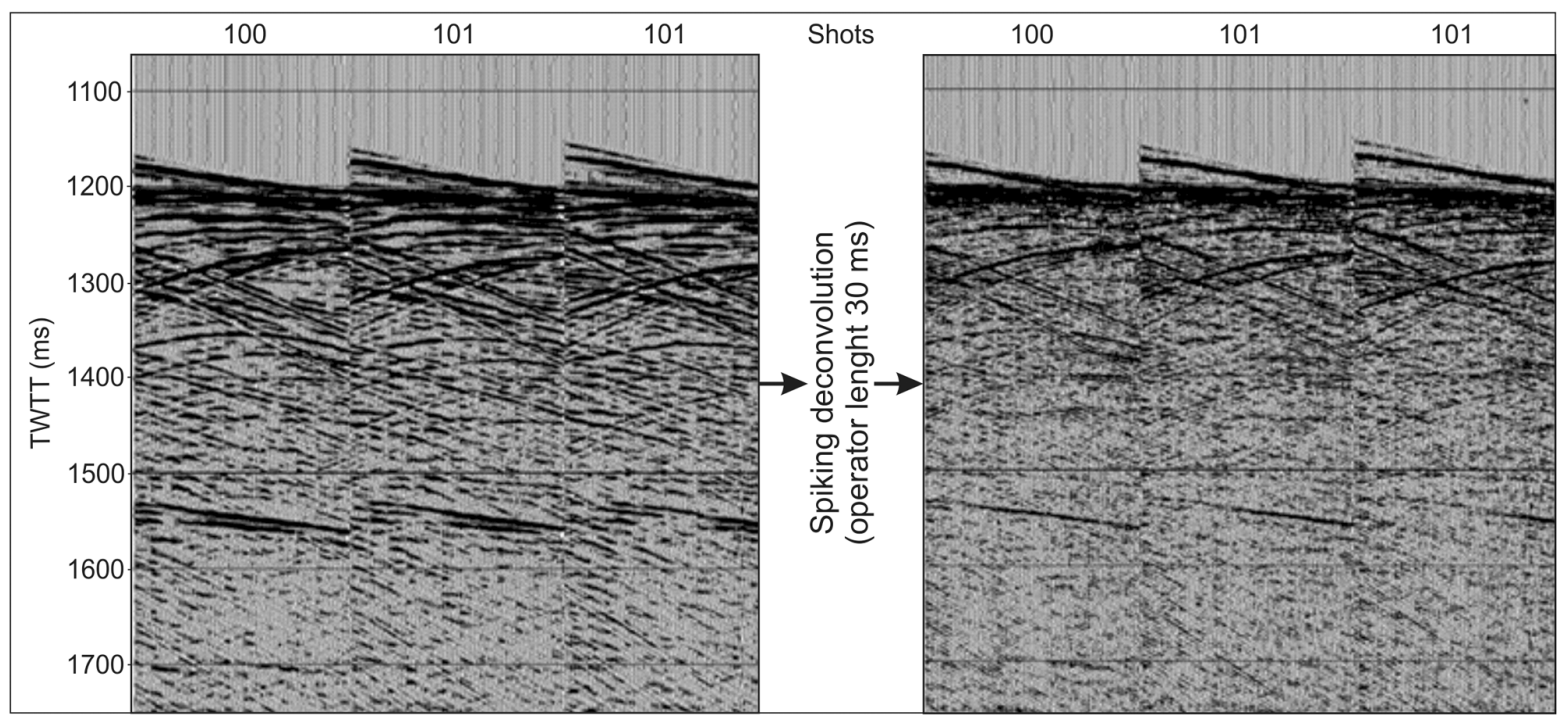

Figure 9. Effects of spiking deconvolution (right) on three pre-processed shots (left) of the line L_I02_HR (Ionian Sea), using an operator length of $30 \mathrm{~ms}$ (see text for further details).

Since spiking deconvolution broadens the data amplitude spectrum, eventually boosting also the undesired frequencies, a wide band-pass filter with the same above mentioned frequency ranges, was re-applied after deconvolution.

\section{CMP sort and velocity analysis (CMP)}

Our data were subsequently sorted into CMP (Figure 10), which involve a re-arrangement of the whole dataset from shot-receiver to midpoint-offset domain. In the approximation of horizontal reflectors, CMP gathers contain the seismic signals originated by rays incident at the same reflection point with different angles.

Before stacking all traces in the CMP gathers, to obtain a "CMP stacked" section we need to remove the offset dependence from the reflected arrivals, so that all reflections from the same interface are in phase. This operation is known as "normal move-out correction" (NMO; Yilmaz [2001] and references therein) and needs an estimate of the P-wave RMS velocity $\left(\mathrm{V}_{\mathrm{RMS}}\right)$ along the line. This phase, commonly called velocity analysis, is performed on selected CMP gathers, with the help of a "velocity spectra", that is a graph showing some measures of signal coherency (such as semblance or normalized cross-correlation: see Yilmaz [2001]) calculated along hyperbolic trajectories, as a function of velocity, offset and travel time. In our case we used the semblance (Figure 11a), as defined in Neidell and Taner [1971]. Generally, together with the semblance functions, it is also useful to display some additional infor-

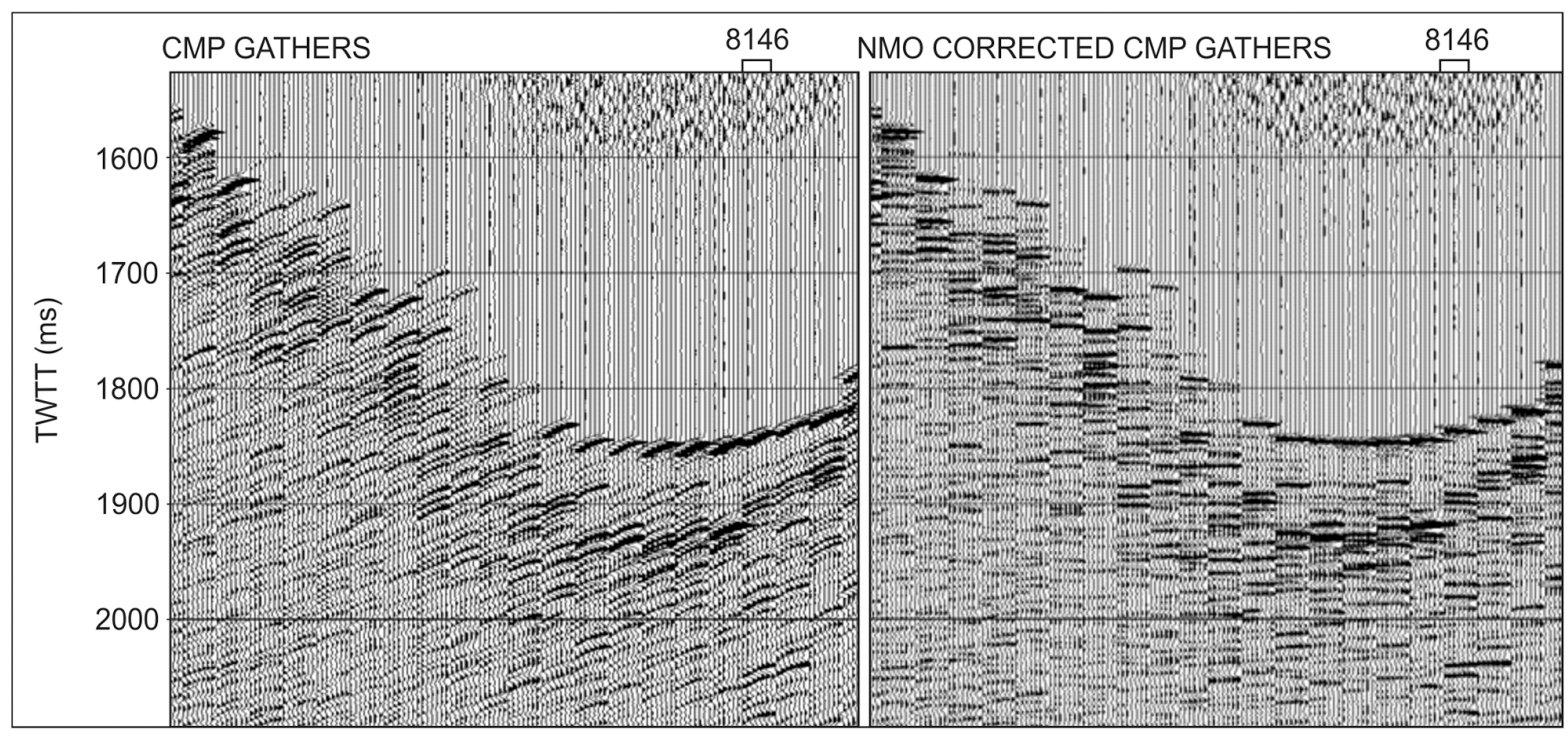

Figure 10. Uncorrected (left) and NMO corrected (right) CMP gathers extracted from the dataset of line L_T19_HR (Tyrrhenian Sea). Each CMP gather is composed of 7 traces, representing the CMP fold coverage. The quality of the velocity function can be verified by inspecting the flatness of the corrected event, that must result horizontally aligned. 


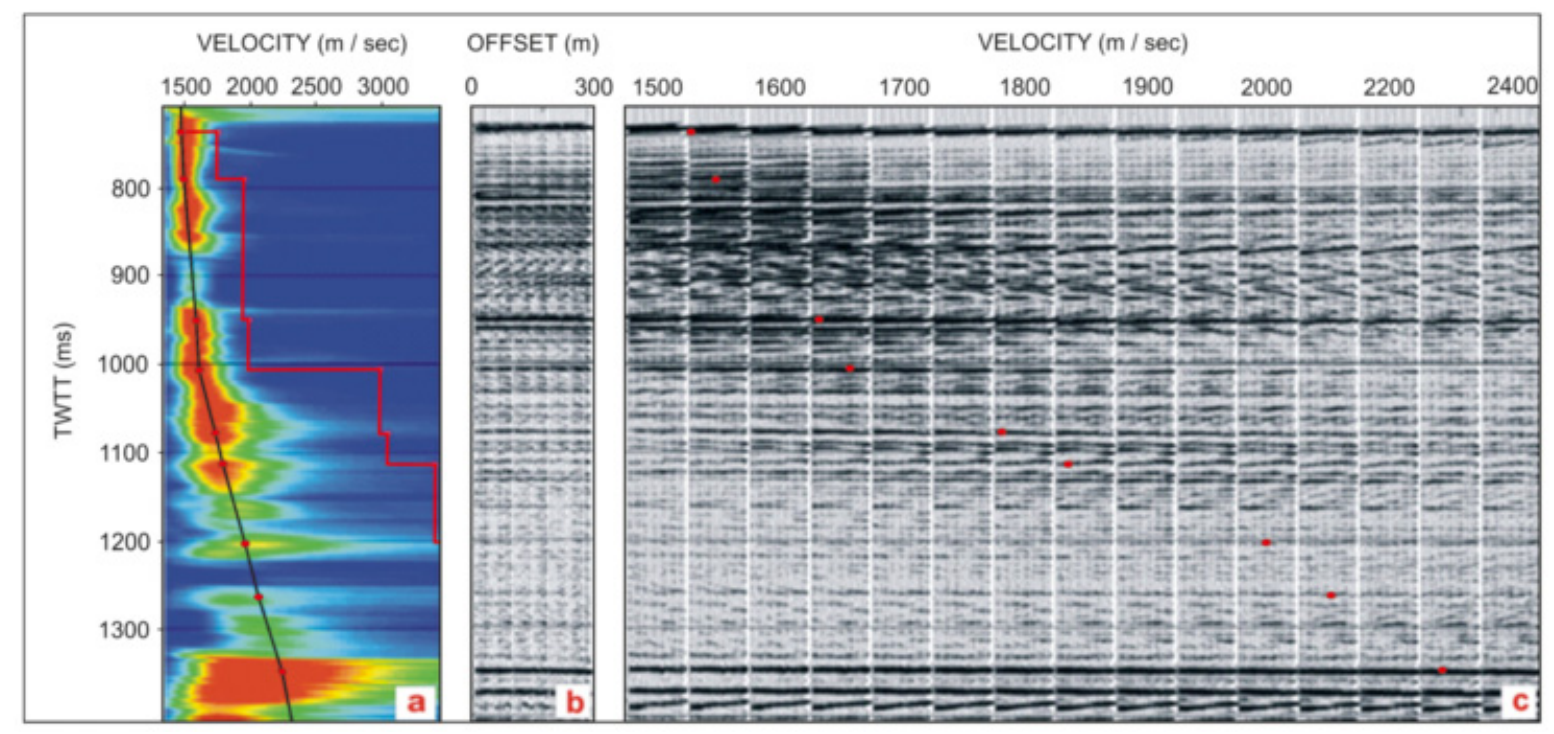

Figure 11. An example of velocity analysis on a CMP of the T_T09_HR profile. In the semblance (a), the RMS velocity function is represented by the solid black line joining the velocity peaks; the corresponding interval velocity function is represented by the solid red line; (b) supergather; (c) constant velocity stack (CVS) panels. Each red dot on the CVSs represents the correspondent velocity pick in the semblance (see text for further details).

mation such as the "supergather" (formed by three adjacent CMP gathers; Figure 11b) and the constant velocity stack (CVS, Figure 11c), resulting from stacking all the data over a limited CMP range (generally not more than 20-25 CMPs) with a constant value of NMO velocity. By picking the maxima of coherency picks on the semblance velocity spectra, which yield an optimal horizontal alignment of the events in the supergather and show a good quality stack on the CVSs we were able to define the $\mathrm{V}_{\mathrm{RMS}}$ as a function of TWTT for each of the selected CMPs.

In the example of Figure 11, it can be seen that our velocity analysis is accurate down to $1200 \mathrm{~ms}$; at later TWTT, many factors as the decreasing in $\mathrm{S} / \mathrm{N}$ ratio, the lack of long offsets (which translates into the lack of significant move-out required for velocity discrimination using the semblance) and the small fold coverage, especially for the HR data (which reduces the power of cross-correlation in measuring signal coherency) have caused loss of resolution in the velocity spectra, making our $\mathrm{V}_{\mathrm{RMS}}$ estimate imprecise. (CMP)

NMO correction, pass-primary f-k filtering and stack

Velocity analysis provided a space and time variant $\mathrm{V}_{\mathrm{RMS}}$ function that was used in the NMO correction of the CMP gathers (Figure 10). As discussed above, NMO correction removes the offset dependency of reflected signals, so that all primary reflections from the same interface are in phase. After NMO correction we converted our CMP gathers from offset vs TTWT dimension ( $\mathrm{x}-\mathrm{t}$ ) into frequency vs wavenumber dimension (f-k). This conversion is sometimes useful to attenuate the multiples on
NMO corrected CMP gathers, as multiples generally are overcorrected with respect to the primary reflections, which are horizontal if their NMO velocity was correctly picked. Under such conditions, primary and multiple reflections were better separated in the $\mathrm{f}-\mathrm{k}$ plane with respect to the $\mathrm{x}$-t plane (for further details see Yilmaz [2001]). f-k filter consisted in zeroing, in the $\mathrm{f}-\mathrm{k}$ amplitude spectrum, all the energy not related to primary events. After filtering, data were converted back to $\mathrm{x}$-t domain. Figure 12 shows the difference between some unfiltered and f-k filtered data of line L_I01_HR. Note that the seafloor multiple was successfully attenuated, while the primary signals remained almost unchanged.

As a result of NMO correction, traces were stretched in a time-varying manner, causing a frequency distortion, which becomes significant for large offsets and shorter times events. A constant mute function was applied in order to remove the events whose percent frequency changed by more than $25 \%$. Successively, NMOcorrected, fk-filtered, and locally muted CMP gathers were horizontally stacked to improve the $\mathrm{S} / \mathrm{N}$ ratio (stacking). The stacked traces, one for each CMP gather, form a stacked seismic section (Figure 13).

Post-stack predictive deconvolution and time-variant band-pass filter (STK)

Under the conditions discussed for spiking deconvolution, Wiener-Levinson matrix equation can be opportunely modified for estimating a filter operator that, convolved with the seismograms, yields a time-advanced form of the input series. This method, which uses the information provided by the traces autocorre- 


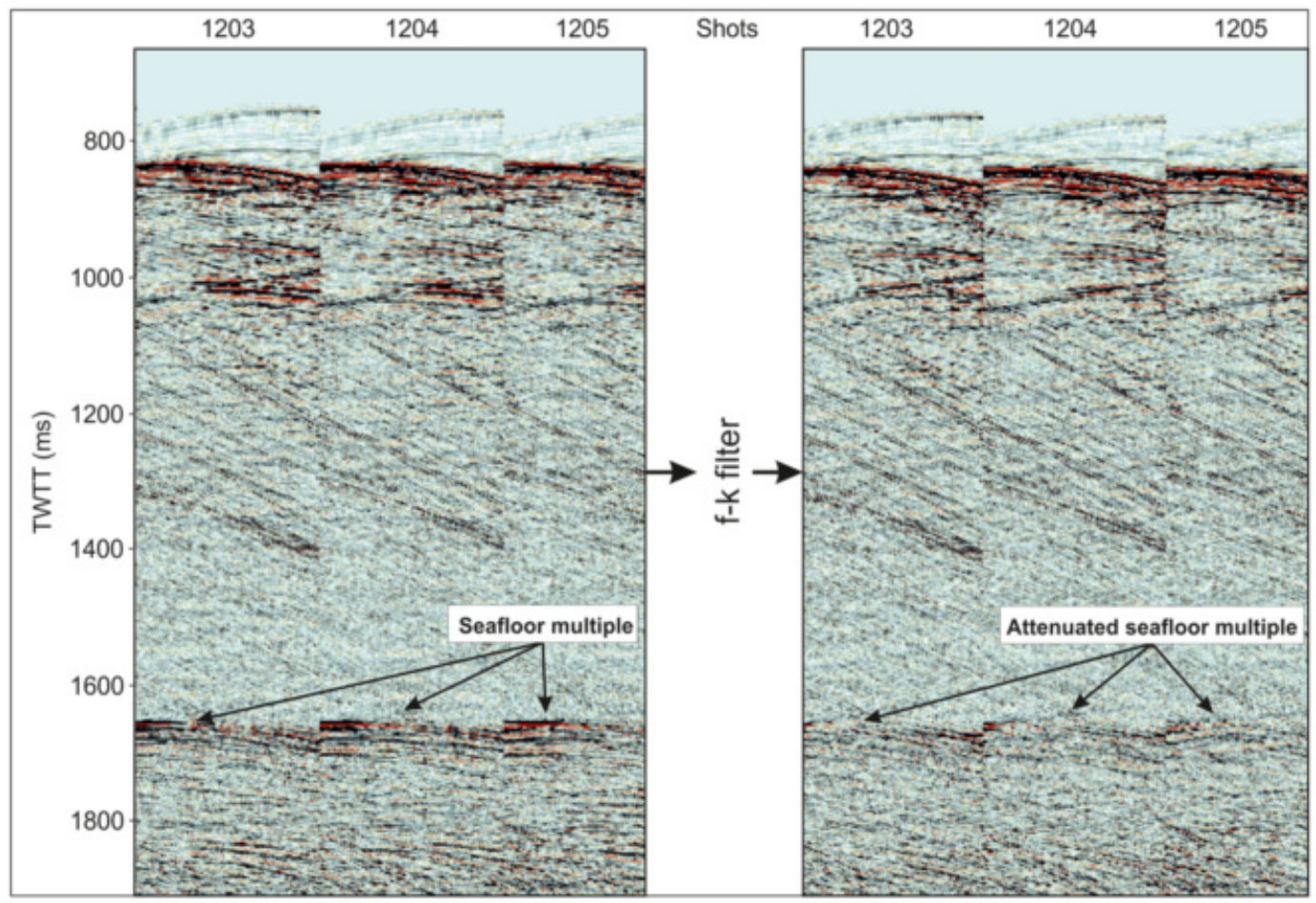

Figure 12. Comparison between three not fk-filtered (left) and fk-filtered (right) shots of the L_I01_HR seismic section (Ionian Sea). Note the seafloor multiple attenuation (see text for further details).

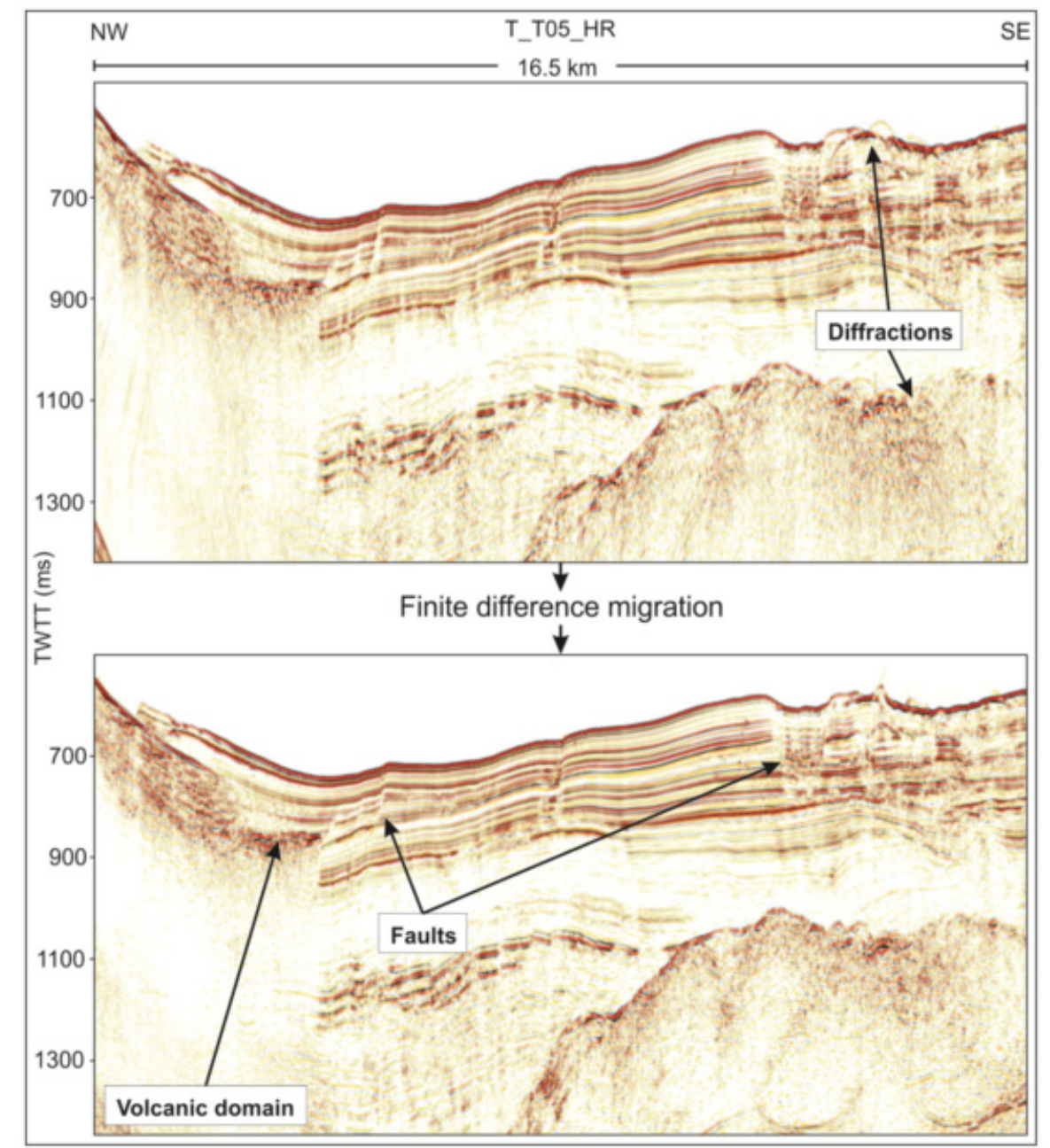

Figure 13. Unmigrated (top) and time-migrated (bottom) stacks of the T_T05_HR line (Tyrrhenian Sea, see Figure 3 for line location). Migration has successfully removed some diffractions previously present in the data, showing better defined reflectors. 
lation, allows a prediction process, based on the assumption that seismic traces often have periodic, and then predictable events (i.e. multiples) and random (unpredictable) components [Yilmaz 2001]. This operation, known as "predictive deconvolution" can be applied to both pre-stack or post-stack domains. Since S/N ratio on post-stack domain is higher, then predictive deconvolution can be more effective on post-stack data; in our case we used post-stack predictive deconvolution to predict the first seafloor multiple; the predicted series was then subtracted from the original data. Figure 14 shows a part of the seismic profile L_I01_HR; an operator length of $20 \mathrm{~ms}$ with a prediction-lag equal to the TWTT of the first sea bottom reflection for each of the CMP stacked traces was sufficient for a good attenuation of the seafloor multiple (see Yilmaz [2001] for further details). Note that deconvolution does not work well in the dipping part of the multiple, since the vertical incidence assumption is violated.

Finally, because high frequencies are absorbed more rapidly than low frequencies, due to intrinsic attenuation in rocks, a time-variant spectral analysis was performed on the stacked sections, to design an appropriate time-variant band-pass filter for further improving $\mathrm{S} / \mathrm{N}$ ratio.

Automatic gain control and n-traces weighted mix (STK)

At this stage of data processing, two gain applications were employed. Generally, at first we applied an automatic gain control (AGC) to the stacked sections, which is a time-variant scaling function that works by calculating the average absolute amplitude within a moving time window in every single seismic trace. The sample at the center of the window is then multiplied by a chosen scale value and divided by the calculated average absolute amplitude. The whole process moves down one sample and starts again. Since smaller TWTT yields higher average amplitudes, AGC generally brings up deeper signals and, in addition, vertically homogenise every single CMP stacked trace. Nevertheless, short time AGC windows can cause a significant loss of signal character; for this reason, large gates of $250-500 \mathrm{~ms}$ were used for mid-shallow data and of 500-2000 ms for deep seismic sections.

After the AGC, a smoothing function across traces was often applied to data (n-traces weighted mix); the algorithm works by adding several (n) traces together with specified weighting to create one output trace. To preserve signal character we mixed only 3 traces, assigning a scale factor of 1 to the central trace and of 0.25 to the adjacent ones; the new central trace is the sum of the 3 weighted traces. The filter was then moved to the next trace and the procedure was repeated.

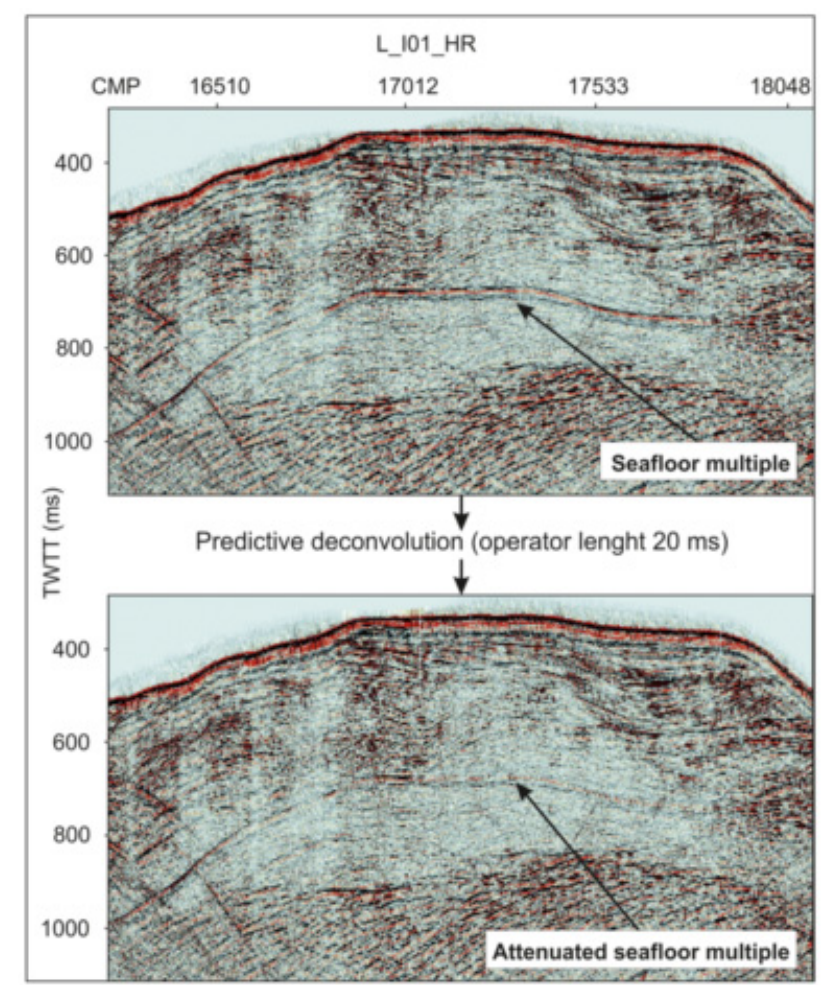

Figure 14. Effects of predictive deconvolution on a portion of a stacked section of the L_I01_HR line (Ionian Sea, see Figure 3 for line location), using an operator length of $20 \mathrm{~ms}$. Note the good attenuation of the sea-floor multiple.

\section{Finite-difference migration (STK)}

Among the many processes applied to seismic data, seismic migration is the most directly associated with the concept of seismic imaging. Without migration, seismic data are simply echoes that have been reflected from the subsurface structure. Migration aims to put reflected events in their correct position in space, laterally as well as vertically. Regardless of the migration approach implemented, the key parameter of the process is a good knowledge of the seismic velocity field. Since migration involves retropropagation of the recorded wavefield back to the reflecting interfaces, a precise estimation of the actual subsurface seismic velocity is essential; for this reason we used a revised, interpolated and smoothed version of the NMO velocity field for time-migrating our seismic sections.

Among the several methods, "finite-difference" migration has been the one that showed the best results on our dataset (see Yilmaz [2001] for further details). In general, migration is the most resource-intensive processing step and, being our analysis only preliminary, we herein report some examples of simple post-stack time migration. Figure 13 and Figure 15 show a comparison between the CMP stacks of respectively the T_T05_HR and a portion of the L_08_MCS lines, and the results obtained by applying a finite-difference poststack time-migration algorithm. Eve at this preliminary 


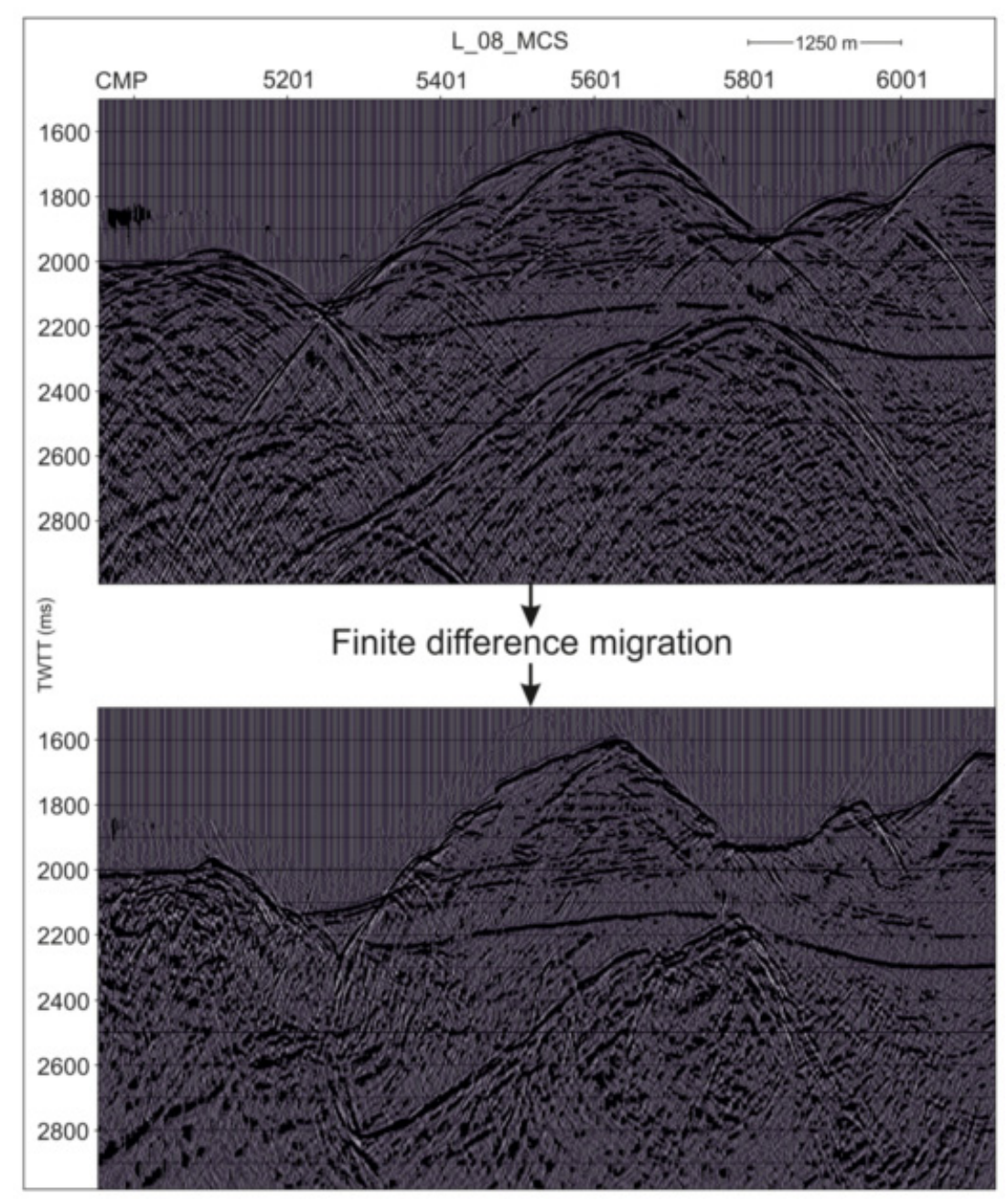

Figure 15. Unmigrated (top) and time-migrated (bottom) stacks of a portion of the L_08_MCS line (Ionian Sea, see Figure 2 for line location).

stage, it is evident that migration successfully imploded diffraction hyperbolas and migrated the dipping reflectors to different space-time locations.

\section{Discussion on preliminary results}

As expected, HR seismic profiles acquired through the R/V "Aegaeo", due to the high frequency content, allow us to well discriminate the shallow reflectors, down to few $\mathrm{km}$ of depth, while the crustal profiles, acquired through the R/V "Sarmiento de Gamboa", show very good results in deep reflections imaging, down to over $9 \mathrm{~s}$ TWTT (i.e. nearly $20 \mathrm{~km}$ considering a mean crustal velocity of $5000 \mathrm{~m} / \mathrm{s}$ ).

Some examples of stacked sections are hereafter shown to highlight the successful acquisition procedures and processing of MCS data acquired during the TOMO-ETNA experiment. Nevertheless, the results discussed below must be considered as preliminary since they need to be integrated and correlated with other geophysical data collected not only during the TOMOETNA experiment (3D tomography, magnetic and gravity data), but also during previous INGV projects and by INGV earthquake and volcano monitoring, to strengthen and validate the geological interpretation.

Figure 16 represents a processed CMP stacked portion of the line T_11_MCS (Ionian Sea), also shown in Figure 5 as a single-channel common-offset section, where only a wide band-pass filter and a constant gain application function were applied. By comparing the two figures, it is quite evident the fundamental importance of the multi-channel method for Earth imaging. The dominant frequency in the shallower portion is about $50 \mathrm{~Hz}$, leading to a vertical resolution of some $10 \mathrm{~m}$. Large scale structures, that were barely visible in the single-trace section (Figure 5), are very well imaged in the processed stack (Figure 16), as the overthrusting of a chaotic seismic facies upon a westward-tilted highreflective sequence of reflectors.

Figure 13 shows an unmigrated (top) and a migrated (bottom) stacks of the T_T05_HR seismic section acquired in the Tyrrhenian Sea. The shallow, 250 to 300 ms thick, stratified sedimentary sequence and the several faults locally displacing it, are very well imaged, yielding an estimated vertical resolution of some 2-3 $\mathrm{m}$. The volcanic deposits, probably belonging to Vulcano Island, appear at the left-hand side of the picture 


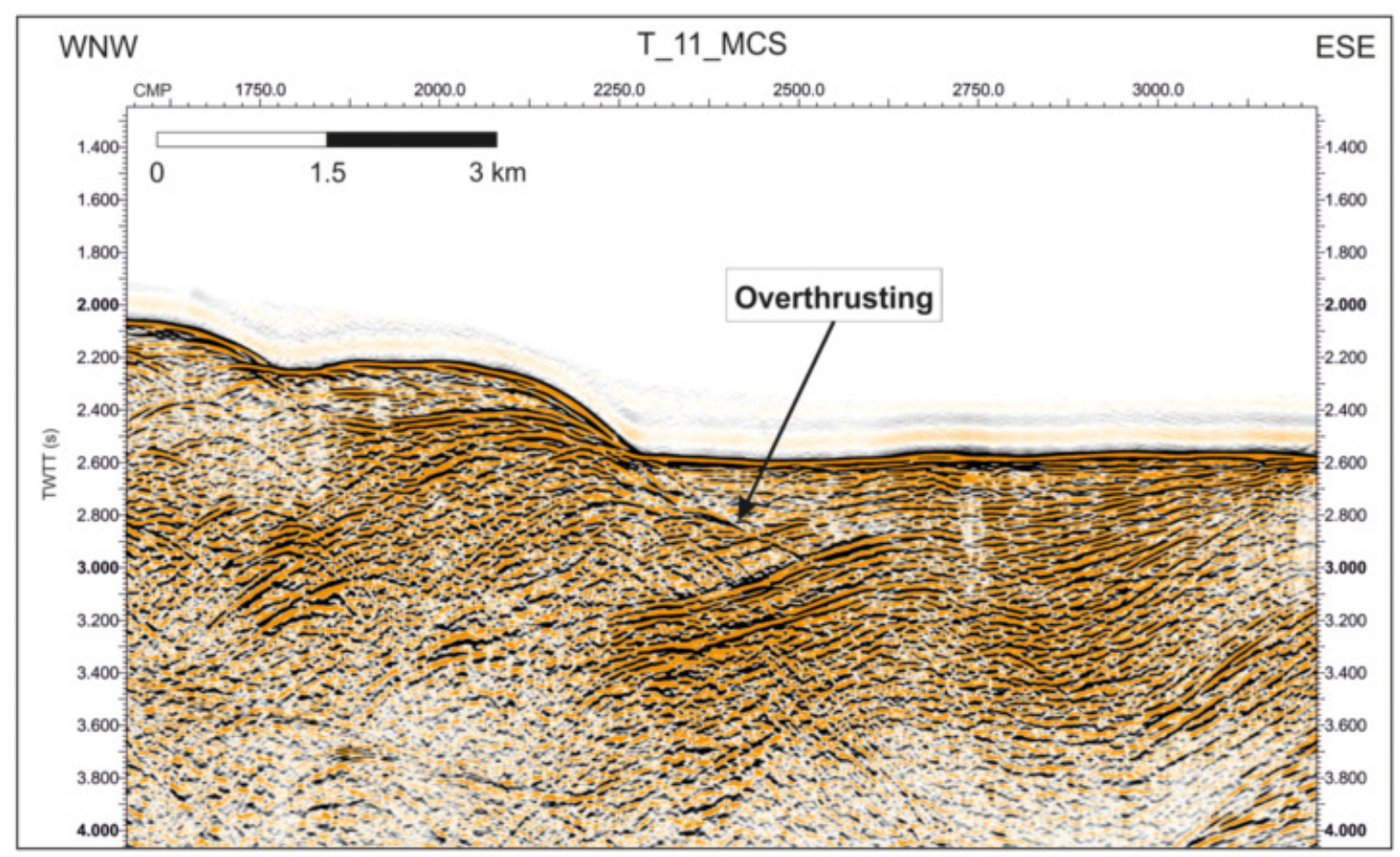

Figure 16. Part of a migrated stack of the T_11_MCS line (Ionian Sea, see Figure 2 for line location). See text for further details.

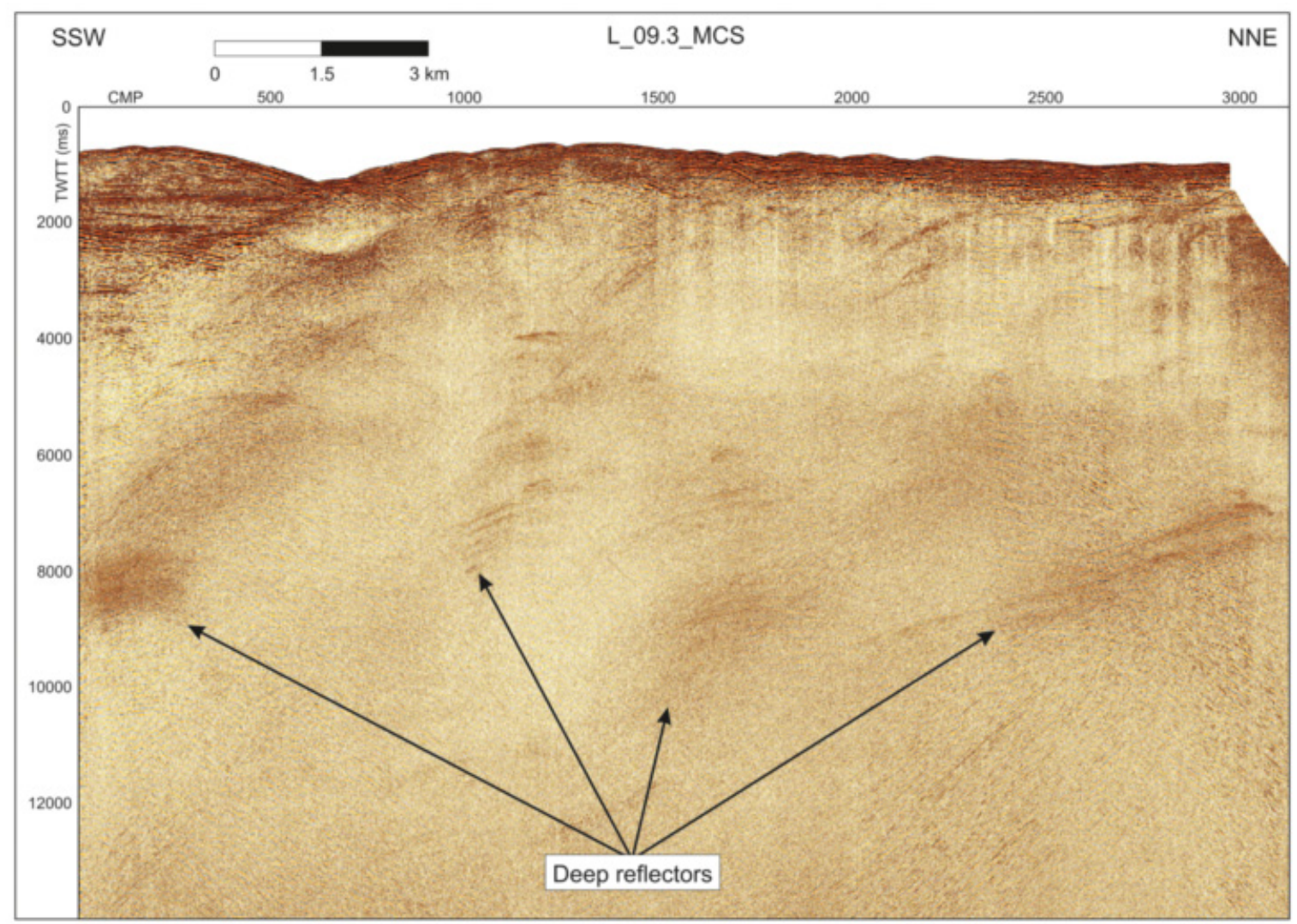

Figure 17. Unmigrated stack of the L_09.3_MCS line (Ionian Sea, see Figure 2 for line location). See text for further details.

as a succession of chaotic reflectors that scatter upward most of the energy, preventing from deeper penetration and thus hampering the interpretation at depth.

Figure 17 shows an unmigrated stack of the line L_09.3_MCS acquired in the Ionian Sea. An accurate data processing was successfully performed for deep seismic imaging. The meaning of the isolated groups of reflectors occurring in the south-central portion of the line, between 4 and 10 s TWTT is less understood; moreover, between 7 and 9 s TWTT, at the CMP interval 2000 -3000, well-defined southward dipping reflectors are shown. Nicolich et al. [2000] interpreted comparable 


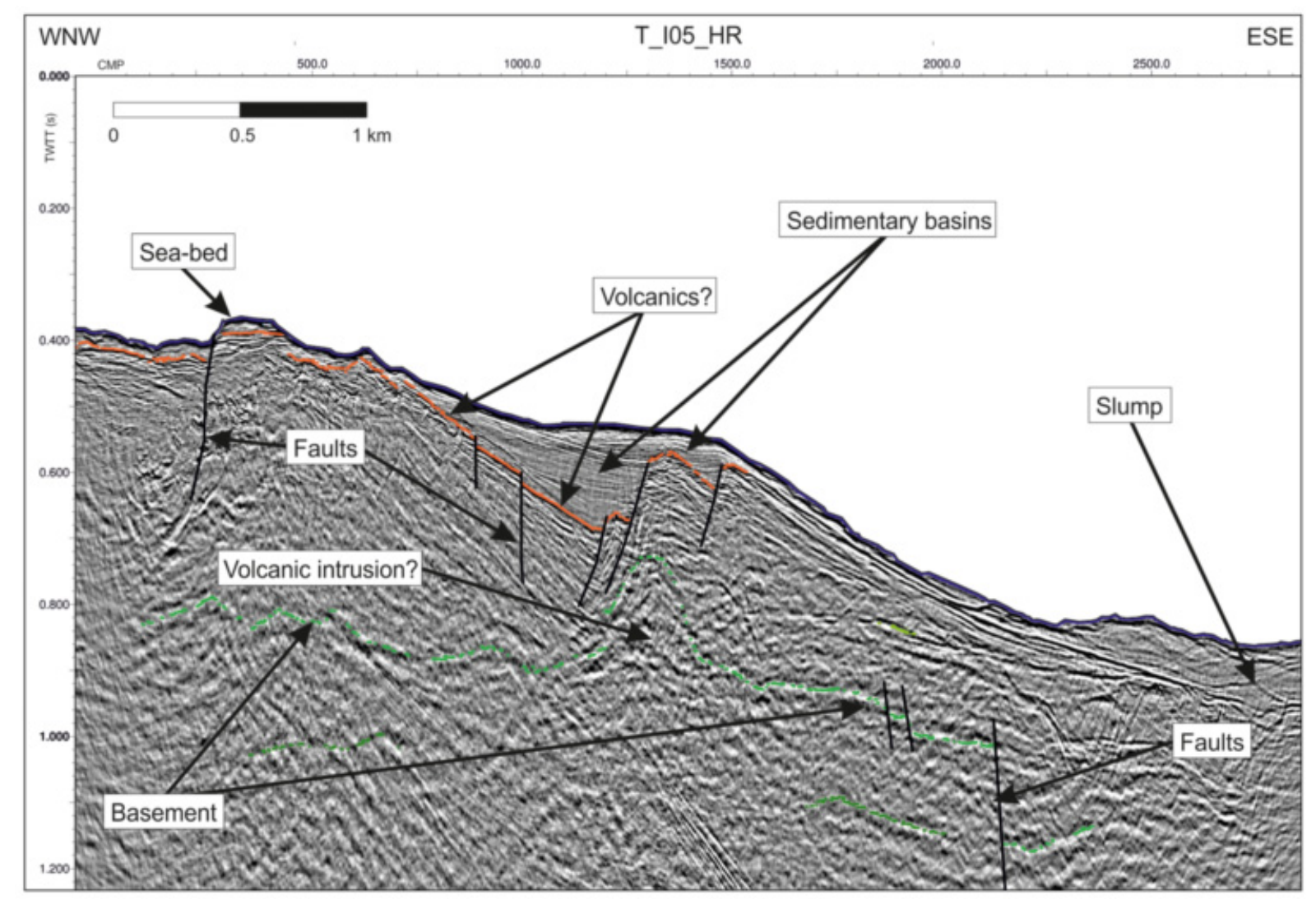

Figure 18. Unmigrated stack of the T_I05_HR line (Ionian Sea, see Figure 3 for line location). See text for further details.

deep reflections found in an adjoining area of the Ionian Sea, as the Moho discontinuity. Such surface was detected on several pre-processed common-offset sections of the deep MCS data, so future processing will be dedicated to identify and possibly map it on the whole study area.

Finally, Figure 18 shows a preliminary interpreted, migrated stack of the T_I05_HR line, acquired in the Ionia Sea to reveal the nature of the morphological high recognized offshore Mt. Etna, between the towns of Aci Trezza and Acireale (Figure 3, bottom), and considered as the underwater portion of a shield volcano [Chiocci et al. 2011], pertaining to the Acireale Synthem (ca $220-130 \mathrm{ka}$ ) of Etna volcano [Branca et al. 2011]. A faulted acoustic basement, with presumed volcanic intrusions, ranges between 0.8 and $1 \mathrm{~s}$ TWTT. The upper reflectors, located at or few tens of meters below the seafloor, possibly related to the presence of volcanics, seem to be cut by several shallow faults, dipping westwards and isolating small highly resolved syn-tectonic sedimentary basins. These faults may be related to shallow gravitational instability, connected to the seaward spreading of the eastern flank of Etna volcano [Borgia et al. 1992, 2000; Chiocci et al. 2011 and references therein].

As a whole, with the exception of the navigation misfit discussed in Paragraph 3.1, no particular issues where encountered during MCS data QC and processing. Both the datasets acquired during the two cruises of the TOMO-ETNA experiment show an overall high
$\mathrm{S} / \mathrm{N}$ ratio, leading to good quality seismic stacks. At present, $\sim 200 \mathrm{~km}$ of seismic sections were preliminarily processed; nevertheless, additional steps will be eventually applied to further increase $\mathrm{S} / \mathrm{N}$ ratio, keeping parsimony in processing, since the preservation of signal character is fundamental for a correct imaging of Earth's interior.

The results of the MCS profiles analysis, together with those produced by the other scientific activities of the TOMO-ETNA experiment, will furnish an essential tool to better constrain the evolution of Etna and Aeolian Island volcanism and, more in general, the geodynamic pattern of the surveyed areas.

Acknowledgements. We thank for their contribution to the success of the research cruises, the captain Thodoros Kanakaris of the R/V "Aegaeo" and his crew; the captain Rafael García Giráldez of the R/V "Sarmiento de Gamboa" and his crew; the commander Melissa Maselli of the "Levanzo" ship of Italian Navy and her crew. This work has been partially funded by: the MED-SUV project, funding from the European Union's Seventh Program (FP7) under grant agreement No. 308665; the Spanish COCSABO project (COCDI-2011-08) and the EUROFLEET 2 MED-SUV.ISES project (EF2SI-005) funding from European Commission. Moreover we would like to thank the following supporting institutions: Unidad de Tecnología Marina-CSIC in Barcelona (Spain); Istituto Nazionale di Oceanografia e Geofisica Sperimentale in Trieste (Italy); Stato Maggiore Marina (Italian Navy General Staff), CINCNAV (Command in Chief of the Fleet) and Marisicilia (Navy Command of Sicily); Coastal Guard of Riposto, Lipari and Messina; Spanish Foreign Office and Italian Foreign Office. We thank the anonimous reviewers 
for improving the final version of this paper. We are grateful to the Schlumberger for the VISTA and to the IHS for the Kingdom software donation. The bathymetric data products have been derived from the EMODnet Bathymetry portal (http:/ / www.emodnet-bathymetry.eu).

\section{References}

Argnani, A., and C. Bonazzi (2005). Malta Escarpment fault zone offshore eastern Sicily: Pliocene-Quaternary tectonic evolution based on new multichannel seismic data, Tectonics, 24, TC4009, doi:10.1029/20 04TC001656.

Argnani, A. (2009). Evolution of the southern Tyrrhenian slab tear and active tectonics along the western edge of the Tyrrhenian subducted slab, In: D.J.J. van Hinsbergen, M.A. Edwards and R. Govers (eds.), Collision and Collapse at the Africa-Arabia-Eurasia Subduction Zone, The Geological Society, London, Special Publications, 311, 193-212.

Argnani, A., G. Brancolini, C. Bonazzi, M. Rovere, F. Accaino, F. Zgur and E. Lodolo (2009). The results of the Taormina 2006 seismic survey: Possible implications for active tectonics in the Messina Straits, Tectonophysics, 476, 159-169, doi:10.1016/j.tecto. 2008.10.029.

Argnani, A., A. Armigliato, G. Pagnoni, F. Zaniboni, S. Tinti and C. Bonazzi (2012). Active tectonics along the submarine slope of south-eastern Sicily and the source of the 11 January 1693 earthquake and tsunami, Nat. Hazards Earth Syst. Sci., 12, 1311-1319.

Argnani, A., F. Mazzarini, C. Bonazzi, M. Bisson and I. Isola (2013). The deformation offshore of Mount Etna as imaged by multichannel seismic reflection profiles, J. Volcanol. Geotherm. Res., 251, 50-64.

Argnani, A. (2014). Comment on the article "Propagation of a lithospheric tear fault (STEP) through the western boundary of the Calabrian accretionary wedge offshore eastern Sicily (Southern Italy)" by Gallais et al., 2013 Tectonophysics, Tectonophysics, 610, 195-199.

Badley, M. (1985). Practical Seismic Interpretation, Springer Netherlands, $257 \mathrm{p}$.

Borgia, A., L. Ferranti and G. Pasquarè (1992). Importance of gravitational spreading in the tectonic and volcanic evolution of Mount Etna, Nature, 357, 231-235.

Borgia, A., R. Lanari, E. Sansosti, M. Tesauro, P. Bernardino, G. Fornaro, M. Neri and J.B. Murray (2000). Actively growing anticlines beneath Catania from the distal motion of Mount Etna's decollement measured by SAR interferometry and GPS, Geophys. Res. Lett., 27(20), 3409-3412.

Branca, S., M. Coltelli, G. Groppelli and F. Lentini (2011) Geological map of Etna volcano, 1:50,000 scale, Ital. J. Geosci., 130(3), 265-291, doi:10.3301/
IJG.2011.15.

Cavallaro, D., L. Cocchi, M. Coltelli, F. Muccini, C. Carmisciano, M. Firetto Carlino, J.M. Ibáñez, D. Patanè, M. Filippone and E. Buttaro (2016). Acquisition procedures, processing methodologies and preliminary results of magnetic and ROV data collected during the TOMO-ETNA experiment, Annals of Geophysics, 59(4), S0431, doi:10.4401/ag-7084.

Chiocci, F.L., M. Coltelli, A. Bosman and D. Cavallaro (2011). Continental margin large-scale instability controlling the flank sliding of Etna volcano, Earth Planet. Sc. Lett., 305, 57-64.

Coltelli, M., et al. (2016). The marine activities performed within the TOMO-ETNA experiment, Annals of Geophysics, 59(4), S0428, doi:10.4401/ag-7081.

De Guidi, G., G. Lanzafame, M. Palano, G. Puglisi, A. Scaltrito and L. Scarfi (2013). Multidisciplinary study of the Tindari Fault (Sicily, Italy) separating ongoing contractional and extensional compartments along the active Africa-Eurasia convergent boundary, Tectonophysics, 588, 1-17.

Gallais, F., M.A. Gutscher, D. Klaeschen and D. Graindorge (2012). Two-stage growth of the Calabrian accretionary wedge in the Ionian Sea (Central Mediterranean): Constraints from depth migrated multichannel seismic data, Mar. Geol., 326/328, 28-45.

Gallais, F., D. Graindorge, M.A. Gutscher and D. Klaeschen (2013). Propagation of a lithospheric tear fault (STEP) through the western boundary of the Calabrian accretionary wedge offshore eastern Sicily (Southern Italy), Tectonophysics, 602, 141-152.

Ghisetti, F. (1979). Relazioni tra strutture e fasi trascorrenti e distensive lungo i sistemi Messina-Fiumefreddo, Tindari-Letojanni e Alia-Malvagna (Sicilia nord-orientale): uno studio microtettonico, Geologica Romana, 18, 23-58.

Grasso, M. and F. Lentini (1982). Sedimentary and tectonic evolution of the eastern Hyblean Plateau (southeastern Sicily) during late Cretaceous to Quaternary time, Palaeogeogr. Palaeocl., 39, 261-280.

Grasso, M., A. De Dominicis and G. Mazzoldi (1990). Structures and tectonic setting of the western margin of the Hyblean-Malta shelf, Central Mediterranean, Ann. Tecton., 4, 140-154.

Gross, F., S. Krastel, J. Geersen, J.H. Behrmann, D. Ridente, F.L. Chiocci, J. Bialas, C. Papenberg, D. Cukur, M. Urlaub and A. Micallef (2016). The limits of seaward spreading and slope instability at the continental margin offshore Mt. Etna, imaged by high-resolution 2D seismic data, Tectonophysics, 667, 63-76.

Ibáñez, J.M., J. Prudencio, A. Díaz-Moreno, D. Patanè, G. Puglisi, B.-G. Lühr, F. Carrión, J.J. Dañobeitia, M. 
Coltelli, F. Bianco, E. Del Pezzo, T. Dahm, V. Willmott and V. Mazauric (2016a). The TOMO-ETNA experiment: an imaging active campaign at Mt. Etna volcano. Context, main objectives, working-plans and involved research projects, Annals of Geophysics, 59(4), S0426, doi:10.4401/ag-7079.

Ibáñez, J.M., et al. (2016b). TOMO-ETNA experiment at Etna volcano: activities on land, Annals of Geophysics, 59(4), S0427, doi:10.4401/ag-7080.

Lanzafame, G., and J.C. Bousquet (1997). The Maltese escarpment and its extension from Mt. Etna to the Aeoloian Islands (Sicily): importance and evolution of a lithosphere discontinuity, Acta Vulcanol., 9, 113-120.

Neidell, N.S., and M.T. Taner (1971). Semblance and other coherency measures for multichannel data, Geophysics, 36(3), 482-497, doi:10.1190/1.1440186.

Nicolich, R., M. Laigle, A. Hirn, L. Cernobori and J. Gallart (2000). Crustal structure of the Ionian margin of Sicily: Etna volcano in the frame of regional evolution, Tectonophysics, 329, 121-139.

Patanè, G., I. Agostino, S. La Delfa and R. Leonardi (2009). Evolution of volcanism around the eastern sector of Mt. Etna, inland and offshore, in the structural framework of eastern Sicily, Phys. Earth Planet. In., 173, 306-316.

Polonia, A., L. Torelli, P. Mussoni, L. Gasperini, A. Artoni and D. Klaeschen (2011). The Calabrian Arc subduction complex in the Ionian Sea: Regional architecture, active deformation, and seismic hazard, Tectonics, 30, TC5018, doi:10.1029/2010TC002821.

Stein, S., and M. Wysession (2003). An introduction to seismology, earthquakes, and Earth structure, Blackwell Publishing Ltd., Oxford, 498 p.

Yilmaz, O. (2001). Seismic data analysis: processing, inversion, and interpretation of seismic data, Society of Exploration Geophysicists; http:// dx.doi.org/10. $1190 / 1.9781560801580$.

\footnotetext{
*Corresponding author: Marco Firetto Carlino, Istituto Nazionale di Geofisica e Vulcanologia, Sezione di Catania, Osservatorio Etneo, Catania, Italy; email: marco.firettocarlino@ingv.it. 